\title{
CYP2E1 potentiation of LPS and TNF $\alpha$-induced hepatotoxicity by mechanisms involving enhanced oxidative and nitrosative stress, activation of MAP kinases, and mitochondrial dysfunction
}

\author{
Yongke Lu $\cdot$ Arthur I. Cederbaum
}

Received: 22 July 2009/Accepted: 14 September 2009/Published online: 2 October 2009

(C) Springer-Verlag 2009

\begin{abstract}
The mechanisms by which alcohol causes cell injury are not clear. A major mechanism that is the focus of considerable research is the role of lipid peroxidation and oxidative stress in alcohol toxicity. Many pathways have been suggested to play a role in how alcohol induces oxidative stress. Considerable attention has been given to alcohol-elevated production of lipopolysaccharide (LPS) and TNF $\alpha$ and to alcohol induction of CYP2E1. These two pathways are not exclusive of each other, however, associations and interactions between them, especially in vivo, have not been extensively evaluated. We have shown that increased oxidative stress from induction of CYP2E1 in vivo sensitizes hepatocytes to LPS and TNF toxicity and that oxidants, such as peroxynitrite, activation of p38 and JNK MAP kinases, inactivation of NF-kB protective pathways and mitochondrial dysfunction are downstream mediators of this CYP2E1-LPS/TNF potentiated hepatotoxicity. This review will summarize studies showing potentiated interactions between these two risk factors in promoting liver injury and the mechanisms involved.
\end{abstract}

Keywords Alcohol - CYP2E1 - Lipopolysaccharide . Oxidative stress · Tumor necrosis factor alpha

\section{Alcohol, oxidative stress and cell injury}

The ability of acute and chronic ethanol treatment to increase production of reactive oxygen species and to

Y. Lu $\cdot$ A. I. Cederbaum $(\square)$

Department of Pharmacology and Systems Therapeutics,

Mount Sinai School of Medicine, Box 1603,

One Gustave L. Levy Place, New York, NY 10029, USA

e-mail: arthur.cederbaum@mssm.edu enhance peroxidation of lipids, protein, and DNA has been demonstrated in a variety of systems, cells, and species, including humans [3]. Despite a tremendous growth in understanding alcohol metabolism and actions, the mechanism(s) by which alcohol causes cell injury are still not clear. A variety of leading mechanisms has been briefly summarized [13, 17, 67], and it is likely that many of them ultimately converge as they reflect a spectrum of the organism's response to the myriad of direct and indirect actions of alcohol. A major mechanism that is a focus of considerable research is the role of lipid peroxidation and oxidative stress in alcohol toxicity. Many pathways have been suggested to play a key role in how ethanol induces "oxidative stress". Some of these include redox state changes (decrease in the $\mathrm{NAD}^{+} / \mathrm{NADH}$ redox ratio) produced as a result of ethanol oxidation by alcohol and aldehyde dehydrogenases; production of the reactive product acetaldehyde as a consequence of ethanol oxidation by all major oxidative pathways; damage to mitochondria which results in decreased ATP production; direct or membrane effects caused by hydrophobic ethanol interaction with either phospholipids or protein components or enzymes; ethanol-induced hypoxia, especially in the pericentral zone of the liver acinus as oxygen is consumed in order for the liver to detoxify ethanol via oxidation; ethanol effects on the immune system, and altered cytokine production; ethanol-induced increase in bacterialderived endotoxin with subsequent activation of Kupffer cells; ethanol induction of CYP2E1; ethanol mobilization of iron which results in enhanced levels of low molecular weight non-heme iron; effects on antioxidant enzymes and chemicals, particularly mitochondrial and cytosolic glutathione; one electron oxidation of ethanol to the 1-hydroxy ethyl radical; conversion of xanthine dehydrogenase to the xanthine oxidase form. Again, many of these pathways are 
not exclusive of one another and it is likely that several, indeed many, systems contribute to the ability of ethanol to induce a state of oxidative stress.

What is the evidence that ethanol-induced oxidative stress plays a role in cell injury? While many studies have shown increases in lipid peroxidation or protein carbonyl formation by alcohol, it is not always clear if these are causes of or consequences of the alcohol-induced tissue injury. Nevertheless, there are many studies, which show that administration of antioxidants or iron chelators or GSH-replenishing agents can prevent or ameliorate the toxic actions of alcohol. The most convincing data that oxidative stress contributes to alcohol-induced liver injury comes from the studies using the intragastric infusion model of alcohol administration. In these studies, alcoholinduced liver injury was associated with enhanced lipid peroxidation, protein carbonyl formation, formation of the 1-hydroxyethyl radical, formation of lipid radicals, decreases in hepatic antioxidant defense especially GSH [35, 39, 63, 65, 87]. Replacement of polyunsaturated fat (required for lipid peroxidation to occur) with saturated fat or medium chain triglycerides in the diets fed to rats intragastrically, lowered or prevented the lipid peroxidation, and the alcohol-induced liver injury. Thus, alcohol plus polyunsaturated fat was required for the injury to occur. Addition of iron, known to generate $\bullet \mathrm{OH}$ and promote oxidative stress, to these diets exacerbated the liver injury [88]. Importantly, addition of antioxidants, such as vitamin E, ebselen, superoxide dismutase, GSH precursors prevented the alcohol-induced liver injury.

In addition to these in vivo studies, in vitro studies with hepatocytes also showed that ethanol could produce oxidative stress and hepatocyte toxicity. Studies with isolated hepatocytes from control rats or chronic ethanol-fed rats indicated that ethanol metabolism via alcohol dehydrogenase results in an increase in ROS production, hepatocyte injury, and apoptosis, reactions blocked by antioxidants $[1,9,47]$. Studies in our laboratory with HepG2 cell lines expressing CYP2E1 showed that addition of ethanol or polyunsaturated fatty acids or iron, or depletion of GSH, resulted in cell toxicity, increased oxidative stress, and mitochondrial damage, reactions prevented by antioxidants [94, 95]. HepG2 cells expressing both CYP2E1 and alcohol dehydrogenase have been valuable in studies on ethanolinduced oxidative stress and cell injury [21,68].

\section{Kupffer cells and alcoholic liver disease}

Kupffer cells are stimulated by chronic ethanol treatment to produce free radicals and cytokines, including tumor necrosis factor alpha (TNF $\alpha$ ), which plays a role in ALD. $[2,34]$. This stimulation is mediated by bacterial-derived endotoxin, and ALD is decreased when Gram-negative bacteria are depleted from the gut by treatment with lactobacillus or antibiotics [66]. The TNF $\alpha$ receptor superfamily consists of several members sharing a sequence homology, the death domain, located in the intracellular portion of the receptor. These "death" receptors, including Fas, TNF-R1, and TRAIL-R1/TRAIL-R2 are expressed in hepatocytes and when stimulated by their respective ligands, FasL, TNF $\alpha$, or TRAIL, hepatocyte injury can occur [99]. Lipopolysaccharide (LPS) is a component of the outer wall of Gram-negative bacteria that normally inhabit the gut. LPS penetrates the gut epithelium only in trace amounts; however, LPS absorption can be elevated under pathophysiological conditions such as alcoholic liver disease [73]. When LPS is released from Gram-negative bacteria and enters the blood stream, the liver tightly regulates the entry and processing of LPS by virtue of its ability to clear LPS and respond to LPS [80]. In addition to its ability to clear LPS, the liver also responds to LPS and produces cytokines. LPS directly causes liver injury by mechanisms involving inflammatory cells such as Kupffer cells, and chemical mediators such as superoxide, nitric oxide, and tumor necrosis factor (TNF $\alpha$ ) and other cytokines [31, 81, 91]. In addition, LPS potentiates liver damage induced by hepatotoxins including ethanol [10, 19, $30,46,59,84]$. In experimental alcoholic liver disease, the combination of LPS and chronic ethanol produces hepatic necrosis and inflammation [30, 46, 59, 84]. Ethanol alters gut microflora, the source of LPS, and ethanol increases the permeability of the gut, thus increasing the distribution of LPS from the gut into the portal circulation (endotoxemia). This causes activation of Kupffer cells, the resident macrophages in liver, resulting in release of chemical mediators including cytokines and ROS and subsequently, alcoholic liver disease [23]. Destruction of Kupffer cells with gadolinium chloride attenuated ALD [2]. A major advance was the finding that anti-TNF $\alpha$ antibodies protect against ALD [34]. NADPH oxidase was identified as a key enzyme for generating reactive oxygen species (ROS) in Kupffer cells after ethanol treatment [42]. Moreover, in mice deficient in a subunit of NADPH oxidase, p47phox, the ethanol-induced increase in ROS and $\mathrm{TNF} \alpha$ and liver injury was decreased [41]. The role of TNF $\alpha$ in ALD was further validated by the findings that the ethanol-induced pathology was nearly blocked in TNF $\alpha$ receptor1 knockout mice [100].

The transcription factor nuclear factor-kappaB (NF-kB) in Kupffer cells regulates activation of many inflammatory genes, including TNF $\alpha$. Endotoxin activates NF-kB, leading to the hypothesis that inhibition of NF-kB in Kupffer cells would prevent ALD [90]. Administration of an adenovirus encoding for the IkB superrepressor to rats chronically infused with ethanol blunted the ethanol-induced activation of NF-kB, TNF $\alpha$ production, and pathological changes. 
A general scheme to explain these results is that chronic ethanol treatment elevates endotoxin levels, endotoxin activates Kupffer cells to produce free radicals via NADPH oxidase, the free radicals activate NF-kB, leading to an increase in production of $\mathrm{TNF} \alpha$, followed eventually by tissue damage [82, 84, 92].

\section{CYP2E1}

CYP2E1 metabolizes a variety of small, hydrophobic substrates including solvents such as chloroform and carbon tetrachloride, aromatic hydrocarbons such as benzene and toluene, alcohols such as ethanol and pentanol, aldehydes such as acetaldehyde, halogenated anesthetics such as enflurane and halothane, nitrosamines such as $\mathrm{N}, \mathrm{N}$-dimethylnitrosamine and drugs such as chlorzoxazone and acetaminophen [12, 43, 50, 75, 77, 79, 83, 98]. From a toxicological point of view, interest in CYP2E1 revolves around the ability of this $\mathrm{P} 450$ to metabolize and to activate many toxicologically important compounds, such as ethanol, carbon tetrachloride, acetaminophen, benzene, halothane, and many other halogenated substrates. Procarcinogens including nitrosamines and azo compounds are effective substrates for CYP2E1. Toxicity by the above compounds is enhanced after induction of CYP2E1, e.g. by ethanol treatment, and toxicity is reduced by inhibitors of CYP2E1 or in CYP2E1 knockout mice [48]. Chlorzoxazone is of special value as its hydroxylated product can readily be assayed in the blood and the ratio of 6-hydroxychlorzoxazone/chlorzoxazone is widely used to assess the approximate levels of CYP2E1 in humans, including alcoholics [26].

Molecular oxygen itself is likely to be a most important substrate for CYP2E1 [11, 93]. CYP2E1, relative to several other P450 enzymes, displays high NADPH oxidase activity as it appears to be poorly coupled with NADPHcytochrome P450 reductase [22, 27]. CYP2E1 was the most efficient P450 enzyme in the initiation of NADPHdependent lipid peroxidation in reconstituted membranes among five different P450 forms investigated. Furthermore, anti-CYP2E1 IgG inhibited microsomal NADPH oxidase activity and microsomal lipid peroxidation dependent on $\mathrm{P} 450$, but not lipid peroxidation initiated by the action of NADPH-cytochrome P450 reductase [22]. In our laboratory, we found that microsomes isolated from rats fed ethanol chronically were about two to threefold more reactive in generating superoxide radical and $\mathrm{H}_{2} \mathrm{O}_{2}$, and in the presence of ferric complexes, in generating hydroxyl radical and undergoing lipid peroxidation [20, 38, 71, 74]. CYP2E1 levels were elevated about three to fivefold in liver microsomes after feeding rats the Lieber-DeCarli diet for 4 weeks. In all the above systems, the enhanced effectiveness of microsomes isolated from the ethanol-fed rats was prevented by addition of chemical inhibitors of CYP2E1 and by polyclonal antibody raised against CYP2E1 purified from pyrazole-treated rats, confirming that the increased activity in these microsomes was due to CYP2E1.

\section{CYP2E1 and alcohol-induced liver injury}

Since CYP2E1 can generate ROS during its catalytic cycle, and its levels are elevated by chronic treatment with ethanol, CYP2E1 has been suggested as a major contributor to ethanol-induced oxidant stress, and to ethanol-induced liver injury [15]. Initial suggestions for a role for CYP2E1 in alcoholic liver injury arose from studies with the intragastric model of ethanol feeding, in which prominent induction of CYP2E1 occurs and significant alcohol liver injury occurs [24, 63, 65, 88]. In these models, large increases in microsomal lipid peroxidation have been observed and the ethanol-induced liver pathology has been shown to correlate with CYP2E1 levels and elevated lipid peroxidation [16, 63, 65, 76]. Experimentally, a decrease in CYP2E1 induction was found to be associated with a reduction in alcohol-induced liver injury [25, 37]. CYP2E1 inhibitors such as diallyl sulfide (DAS) [62], phenethyl isothiocyanate (PIC) [4, 64] and chlormethiazole [28], blocked the lipid peroxidation and ameliorated the pathologic changes in ethanol-fed rats. Polyenylphosphatidylcholine (PPC), another compound exerting anti-CYP2E1 properties [5] was effective in opposing alcohol-induced oxidative stress [51]. A strong association between dietary carbohydrate, enhanced CYP2E1 induction, and hepatic necrosis was observed. No liver injury was found if carbohydrate levels were elevated [45]. Ethanol consumption in liquid diets does not cause liver injury. However, micro and macrovesicular steatosis, occasional inflammatory foci and a threefold increase in transaminase levels were observed in a nutritionally adequate ethanol containing liquid diet with a carbohydrate content of 5.5\%; no changes were found if the level of carbohydrate was elevated to $11 \%$ [49, 52]. Thus, dietary and nutritional factors play a key role in the toxic actions of ethanol to the liver, in part, due to modulation of the levels of CYP2E1. A CYP2E1 transgenic mouse model was developed that overexpressed CYP2E1. When treated with ethanol, the CYP2E1 overexpressing mice displayed higher transaminase levels and histological features of liver injury compared with the control mice [61]. We developed an adenoviral vector, which expresses human CYP2E1 and showed that infection of HepG2 cells with this adenovirus potentiated acetaminophen toxicity as compared to HepG2 cells infected with a LacZ expressing adenovirus [6]. Administration of the CYP2E1 adenovirus in vivo to mice elevated CYP2E1 levels and activity and 
produced significant liver injury compared to the LacZinfected mice as reflected by histopathology and elevated transaminase levels [7].

On the other hand, studies by Thurman and colleagues have presented powerful support for a role for endotoxin, activation of Kupffer cells and cytokines such as TNF $\alpha$ in the alcohol-induced liver injury found with the intragastric infusion model $[92,100]$. They suggested that CYP2E1 may not play a role in alcohol liver injury based upon studies with gadolinium chloride or CYP2E1 knockout mice [40, 44]. However, as discussed elsewhere [56, 85], induction by ethanol of other CYPS or of the reductase in the CYP2E1 knockout mice might have served as alternative sources of oxidative stress in these mice, especially in the absence of CYP2E1. Bradford et al. [14] using CYP2E1 and NADPH oxidase knockout mice concluded that CYP2E1 was required for ethanol induction of oxidative stress to DNA, whereas NADPH oxidase was required for ethanol-induced liver injury. Clearly, further studies are necessary to resolve the above discrepancies. As mentioned earlier, it is likely that several mechanisms contribute to alcohol-induced liver injury, and that ethanolinduced oxidant stress is likely to arise from several sources, including CYP2E1, mitochondria, and activated Kupffer cells.

\section{LPS/TNF $\alpha$-CYP2E1 interactions}

As discussed above abnormal cytokine metabolism is a major feature of alcoholic liver disease. Rats chronically fed ethanol were more sensitive to the hepatotoxic effects of administration of LPS and had higher plasma levels of $\mathrm{TNF} \alpha$ than control rats $[33,36]$. In the intragastric model of chronic ethanol administration, the development of liver injury coincided with an increase in $\mathrm{TNF} \alpha$, associated with an increase in serum LPS [84]. Anti-TNF $\alpha$ antibody prevented alcohol liver injury in rats [34] and mice lacking the TNFR1 receptor did not develop alcohol liver injury [100]. Taken as a whole, these and other studies clearly implicate $\mathrm{TNF} \alpha$ as a major risk factor for the development of alcoholic liver injury. One complication in this central role for $\mathrm{TNF} \alpha$ is that hepatocytes are normally resistant to $\mathrm{TNF} \alpha$ induced toxicity. This led to the hypothesis that besides elevating TNF $\alpha$, alcohol somehow sensitizes or primes the liver to become susceptible to $\mathrm{TNF} \alpha[72,86]$. Known factors which sensitize the liver to TNF $\alpha$ are inhibitors of mRNA or protein synthesis, which likely prevent the synthesis of protective factors, inhibition of NF- $\kappa \mathrm{B}$ activation in hepatocytes to lower synthesis of such protective factors, depletion of GSH, especially mitochondrial GSH, lowering of S-adenosyl methionine (SAM) coupled to elevation of S-adenosyl homocysteine (SAH), i.e. a decline in the SAM/ $\mathrm{SAH}$ ratio, or inhibition of the proteasome. Combined treatment with ethanol plus $\mathrm{TNF} \alpha$ is more toxic to hepatocytes and HepG2 E47 cells which express high levels of CYP2E1 than control hepatocytes with lower levels of CYP2E1 or HepG2 C34 cells which do not express CYP2E1 [69]. RALA hepatocytes with increased expression of CYP2E1 were sensitized to TNF $\alpha$ mediated cell death [54]. These results suggest that increased oxidant stress from CYP2E1 may sensitize isolated hepatocytes to TNF $\alpha$-induced toxicity.

Either LPS or CYP2E1 are considered independent risk factors involved in alcoholic liver disease, but mutual relationships or interactions between them are unknown. Toxic interactions between CYP2E1 and TNF $\alpha$ have been reported in vitro $[53,54,69,70]$ and it would be of importance to evaluate whether CYP2E1 contributes or potentiates LPS- mediated liver injury in vivo. The overall objective of the rest of this review is to explore the susceptibility and possible synergistic effect of CYP2E1 overexpression on LPS and TNF hepatotoxicity. These studies may provide an experimental model to better understand mechanisms of ethanol-induced liver damage.

\section{Pyrazole potentiates LPS toxicity [55, 57]}

Male, Sprague-Dawley rats (160-180 g) were injected intraperitonally with pyrazole, $200 \mathrm{mg}$ per $\mathrm{kg}$ body wt, once a day for 2 days to induce CYP2E1. After an overnight fasting, either saline or LPS (Sigma, serotype 055: $\mathrm{BS}, 10 \mathrm{mg} / \mathrm{kg}$ body wt) was injected via the tail vein. Rats were killed $8-10 \mathrm{~h}$ after the LPS or saline injection and blood and liver tissue were collected. Neither pyrazole alone nor LPS alone caused liver injury as reflected by transaminase (ALT, AST) levels or liver histopathology (Fig. 1). However, the combination of LPS plus pyrazole increased AST and ALT levels about four-fold over the levels in the pyrazole alone or LPS alone groups (Fig. 1). LPS plus pyrazole treatment induced extensive necrosis of hepatocytes, mainly located both in periportal and pericentral zones of the liver, accompanied by strong infiltration of inflammatory cells (Fig. 1). LPS alone treatment caused some apoptosis and activation of caspases 3 and 9, whereas pyrazole treatment alone had no effect. LPS plus pyrazole treatment was not any more effective than LPS alone in increasing apoptosis, unlike the increases in necrosis and inflammation.

To assess whether oxidative stress occurs after the various treatments, malondialdehyde (MDA) levels as a reflection of lipid peroxidation, were assayed. Whereas pyrazole alone or LPS alone did not elevate MDA levels over those found with saline controls, the combination of LPS plus pyrazole increased MDA levels about 65\% ( $\mathrm{p}<0.05$ compared to the other 3 groups). Protein carbonyl formation as a marker for oxidized protein formation 

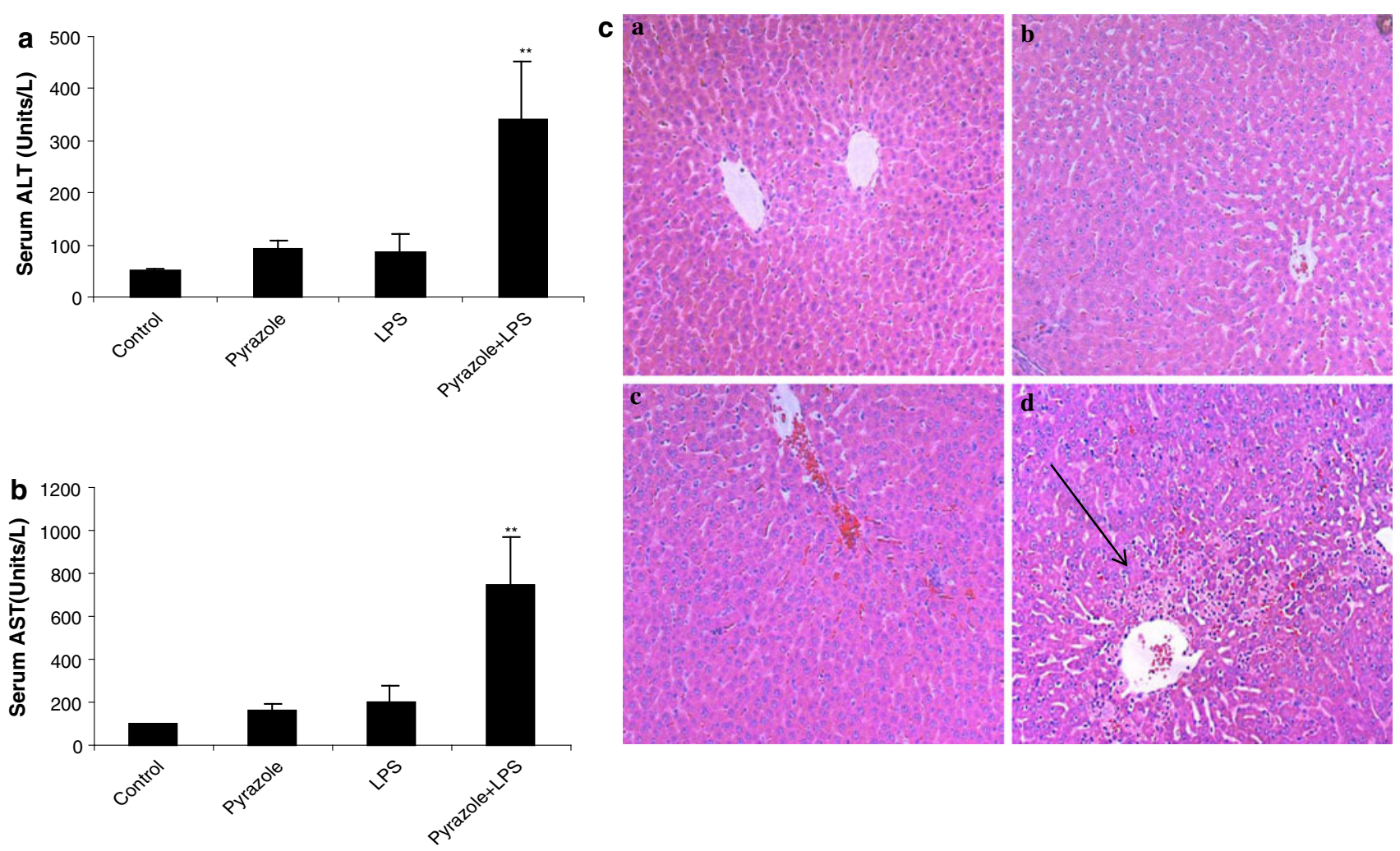

Fig. 1 Effect of pyrazole or LPS or LPS plus pyrazole on serum ALT (a) or AST (b) or liver histopathology (c). In c, panels refer to $a$ saline, $b$ pyrazole-treated, $c$ LPS-treated, $d$ LPS plus pyrazole treated.

was determined. Low levels of protein carbonyls were found in saline control livers. Either treatment with LPS alone or pyrazole alone elevated protein carbonyl levels, however, striking increases in protein carbonyls were found in the combined LPS plus pyrazole group. In situ detection of superoxide was measured using the oxidationdependent fluorescent dye dihydroethidum. Red fluorescence was weak in saline control livers, was slightly increased in either the LPS or pyrazole livers, and was highest in the LPS plus pyrazole livers. 3-Nitrotyrosine (3-NT) protein adducts were detected by a slot blot technique. 3-NT adducts were highest in livers from the LPS plus pyrazole treated mice. Thus, several parameters of oxidative/nitrosative stress were elevated in livers from the LPS plus pyrazole-treated mice.

CYP2E1 catalytic activity (oxidation of $P$-nitrophenol to $p$-nitrocatechol) was increased about twofold by the pyrazole alone or the pyrazole plus LPS treatments. LPS alone slightly decreased CYP2E1 activity but not significantly. Levels of CYP2E1 protein, measured by immunoblot analysis, showed similar trends, being increased about twofold by pyrazole or pyrazole plus LPS treatments. These results show that pyrazole treatment enhanced LPSinduced necrosis, not apoptosis. This enhanced liver injury is associated with elevated levels of CYP2E1 and increased
Arrows show necrotic foci with inflammatory cell infiltration. $* * p<0.01$ compared to all other groups

oxidative/nitrosative stress generated by the combination of LPS plus elevated CYP2E1.

To validate the role of CYP2E1 in the potentiation of LPS toxicity by pyrazole, experiments with chlormethiazole (CMZ) an inhibitor of CYP2E1 and with CYP2E1 knockout mice were carried out [55]. C57BL/6 mice were injected intraperitoneally with pyrazole, $150 \mathrm{mg} / \mathrm{kg}$ body wt once a day for 2 days or $0.9 \%$ saline. After an overnight fast, LPS, $4 \mathrm{mg} / \mathrm{kg}$ body wt or saline was injected IP. CMZ was injected in some mice at a concentration of $50 \mathrm{mg} / \mathrm{kg}$ body wt $15 \mathrm{~h}$ before and $30 \mathrm{~min}$ after the LPS treatment. Mice were killed 3,8 , or $24 \mathrm{~h}$ after LPS or saline injection. In other experiments, CYP2E1 knockout mice, kindly provided by Dr. Frank Gonzalez, NCI, NIH, and their genetic background SV129 controls were treated with pyrazole and LPS as above. Initial experiments showed that neither pyrazole alone nor LPS alone produced liver injury under those conditions. However, the LPS plus pyrazole treatment produced significant liver injury in mice, as was previously shown in rats. Little injury occurred at 3 or $8 \mathrm{~h}$ after the LPS administration, but did occur at $24 \mathrm{~h}$. The injury in the LPS plus pyrazole treated mice was associated with an elevation in oxidative/nitrosative stress as reflected by increases in 3-NT and 4-hydroxynonenal (HNE) protein adducts. Administration of CMZ to the LPS plus pyrazole-treated 
mice decreased the elevated ALT and AST levels by about 55 and 65\%, respectively (Fig. 2). Pathological evaluation showed large necrotic areas in the livers from the LPS plus pyrazole treated mice, but only small necrotic foci were observed after treatment with CMZ (Fig. 2). The treatment with $\mathrm{CMZ}$ also lowered the elevated oxidative/nitrosative stress produced by the LPS plus pyrazole treatment as only weak signals for formation of 4-HNE adducts and 3-NT adducts were found after the CMZ treatment (Fig. 2). The pyrazole plus LPS treatment produced a twofold increase in CYP2E1 catalytic activity, which was prevented after the administration of CMZ. Thus, CMZ blocked the elevation of CYP2E1 in the LPS plus pyrazole treated mice, and this was associated with a decline in oxidative/nitrosative stress and blunting of liver injury.

To further evaluate a role for CYP2E1 in the LPS plus pyrazole toxicity, CYP2E1 knockout or wild type control SV129 mice were treated with LPS plus pyrazole. As with C57B1/6 mice, liver injury was observed in the wild type SV129 mice treated with LPS plus pyrazole, but not mice treated with LPS alone or pyrazole alone. Serum ALT and AST levels were about 50\% lower in LPS plus pyrazole treated CYP2E1 knockout mice as compared to wild type mice (Fig. 3). Pathological evaluation showed large necrotic areas and widespread necrotic foci in wild type mice whereas almost normal histology was found in the LPS plus pyrazole treated CYP2E1 knockout mice. Positive TUNEL staining was also significantly lower in the CYP2E1 null mice compared to wild type mice. Immunoblots confirmed the absence of CYP2E1 protein in the knockout mice while strong signals from CYP2E1 were detected in immunoblots of the wild type mice. Thus, in both rats and mice, the CYP2E1 inducer pyrazole potentiates LPS-induced liver injury. This potentiation is associated with elevated oxidative/nitrosative stress and is blocked by the CYP2E1 inhibitor CMZ, and blunted in CYP2E1 knockout mice. We hypothesize that CYP2E1mediated oxidative stress may synergize with LPS-generated oxidative stress in this model to produce liver injury.

\section{Pyrazole potentiates TNF $\alpha$ toxicity [96]}

Since TNF $\alpha$ levels are elevated after LPS administration and $\mathrm{TNF} \alpha$ plays an important role in the effects of LPS, we determined if pyrazole treatment to induce CYP2E1 potentiates TNF $\alpha$ toxicity as it did LPS toxicity. Basically, the same approaches described above were used, with injection of $\mathrm{TNF} \alpha(50 \mu \mathrm{g} / \mathrm{kg}$ body wt.) replacing the LPS treatment.

Figure 4 shows that ALT and AST levels were low in the saline control mice and in the pyrazole-treated mice challenged with saline. Treatment of control mice with $\mathrm{TNF} \alpha$ elevated transaminase levels by about two to threefold. Treatment of the pyrazole mice with TNF $\alpha$ elevated transaminase levels more than threefold over the TNF $\alpha$-saline control treated mice. Liver sections were stained with H\&E for morphological evaluation. The saline and $\mathrm{TNF} \alpha$ treated mice showed normal liver morphology. Liver from pyrazole treated mice showed some vacuolar degeneration. Liver from the TNF $\alpha$ plus pyrazole treated mice showed several necrotic loci (arrows), typical pathology morphology changes including nuclear pyknosis, karyorrhexis and karyolysis were observed (Fig. 4). The treatment with pyrazole did not significantly alter the levels of thiobarbituric acid-reactive substrates (TBARS) in the total liver extract or the mitochondria (Fig. 4). TNF $\alpha$ treatment of control mice elevated levels of TBARS about two to threefold. TBARS in the homogenates and the mitochondria were further elevated when $\mathrm{TNF} \alpha$ was administered to the pyrazole-treated mice. Highest liver and mitochondrial TBARs levels were observed in the pyrazole plus TNF $\alpha$ treated mice (Fig. 4). Liver GSH levels were similar in the saline, pyrazole-treated, and TNF $\alpha$-treated mice but were decreased about $40 \%$ in the liver extracts from the pyrazole plus TNF $\alpha$ treated mice (Fig. 4). GSH levels were lowered $40 \%$ in the liver mitochondria from the pyrazole plus $\mathrm{TNF} \alpha$-treated mice compared to the TNF $\alpha$ alone treated mice (Fig. 4). These results suggest that the combined pyrazole plus TNF $\alpha$ treatment produces elevated oxidative stress in the liver compared to TNF $\alpha$ alone or pyrazole alone, and that mitochondrial oxidative stress may occur in livers of the pyrazole plus $\mathrm{TNF} \alpha$-treated mice.

As expected, CYP2E1 activity as reflected by the NADPH-dependent microsomal oxidation of $p$-nitrophenol, and the content of CYP2E1 (Western blot analysis) were elevated two to threefold by pyrazole or by pyrazole plus $\mathrm{TNF} \alpha$ treatment, over the saline or $\mathrm{TNF} \alpha$ alone treated mice. Thus, TNF $\alpha$ alone or in combination with pyrazole did not alter CYP2E1 activity or content. In addition, induction of CYP2E1 alone by pyrazole is not sufficient to induce liver injury; rather, a second "hit", e.g. TNF $\alpha$ is required. What is the evidence that induction of CYP2E1 by pyrazole is important for the elevated injury found in the pyrazole plus $\mathrm{TNF} \alpha$-treated mice? We used CYP2E1 knockout mice to address this question. Large increases in ALT and AST levels were found after TNF $\alpha$ administration to pyrazole-treated SV129 wild type mice. TNF $\alpha$ treatment of pyrazole-treated CYP2E1 knockout mice did not elevate transaminase levels (Fig. 5). Similarly, TBARs levels in liver homogenates and isolated mitochondria were not elevated in the TNF $\alpha$ plus pyrazole-treated CYP2E1 knockout mice but were increased in the wild type mice. Normal liver pathology was observed after pyrazole plus TNF $\alpha$ treatment of CYP2E1 knockout mice. (Fig. 5). The failure of $\mathrm{TNF} \alpha$ to induce liver injury in pyrazole-treated 
Fig. 2 The CYP2E1 inhibitor, chlormethiazole, protects against LPS plus pyrazole toxicity and oxidative/ nitrosative stress in mice. Sal Saline-treated, $P+L$ pyrazole plus LPS treated, $C+P+L \mathrm{CMZ}$ plus pyrazole plus LPS treated. a ALT/AST levels.

b histopathology, c 4-HNE adducts, d 3-NT adducts. For $\mathbf{b}, \mathbf{c}$ and $\mathbf{d}$, panels $a$ are the saline treated; panels $b$ are the LPS plus pyrazole treated; panels $c$ refer to the $\mathrm{CMZ}$ plus LPS plus pyrazole treated a

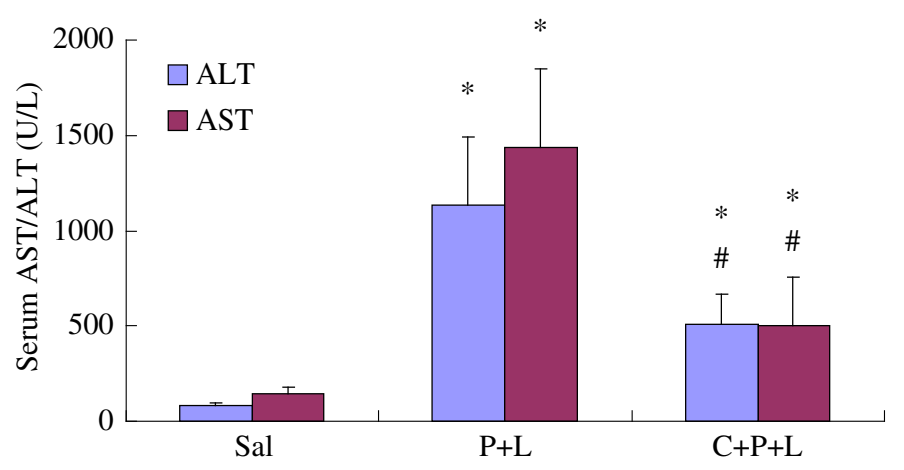

b
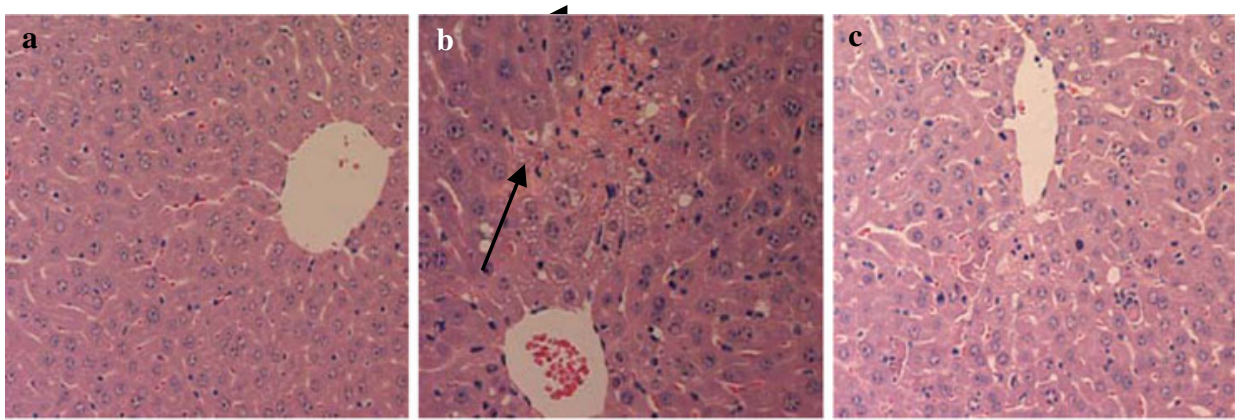

C
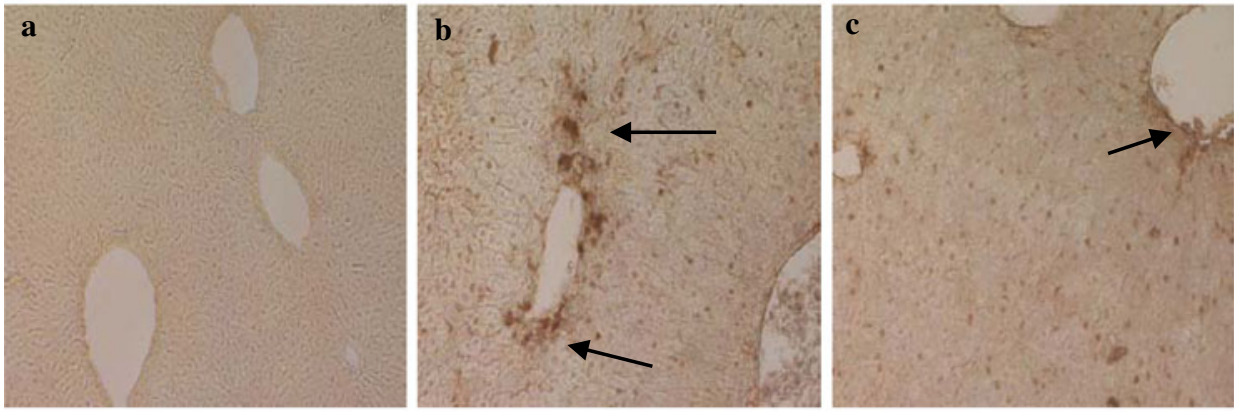

d
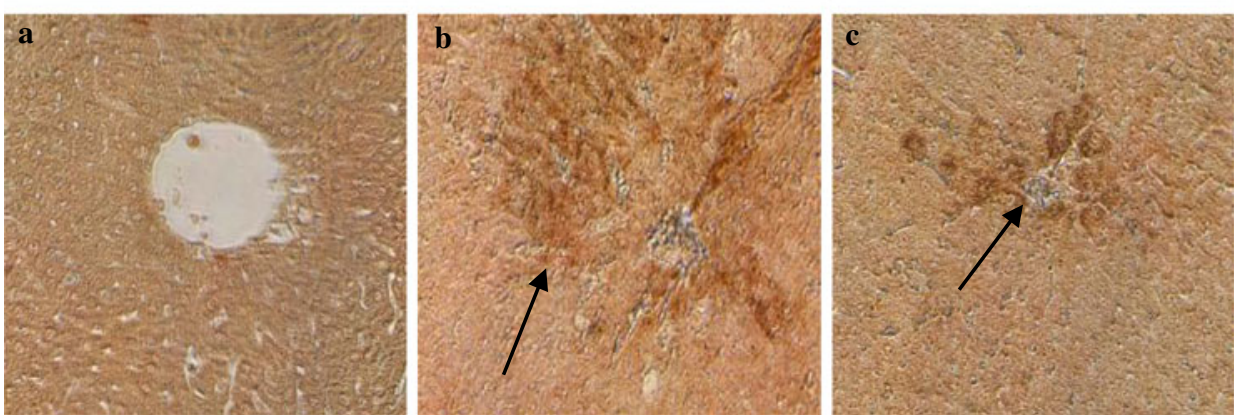

CYP2E1 knockout mice supports a critical role for CYP2E1 in the potentiated injury observed in the wild type mice.

\section{Activation of MAP kinases}

MAP kinases such as JNK or p38 MAPK have been shown to play important roles in several models of liver injury, including CYP2E1-dependent toxicity [18, 29, 53, 54, 69, 70, 78, 89]. We evaluated possible activation of MAP kinases by assaying for the phosphorylated MAPK. As shown in Fig. 6, TNF $\alpha$ treatment alone did not cause significant JNK activation or p38 MAPK activation as reflected by the low p-JNK and pp38 MAPK levels relative to total JNK and p38 MAPK levels. Similar low ratios were found for the saline or the pyrazole alone treated mice (data not shown). However, both JNK and p38 MAPK were activated in livers of the pyrazole plus TNF $\alpha$ treated mice. ERK was not altered by either TNF $\alpha$ alone or pyrazole plus TNF $\alpha$ treatment. To evaluate the significance of these changes in MAPK activation, the effect of SP600125, an inhibitor of JNK, and SB203580, an inhibitor of p38MAPK 


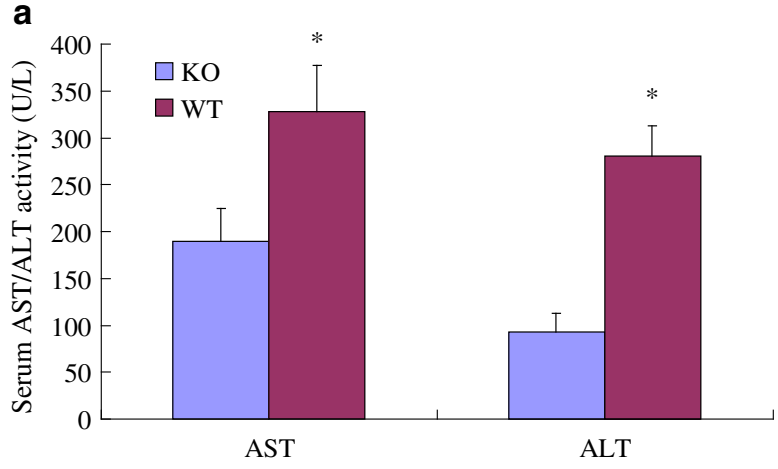

C

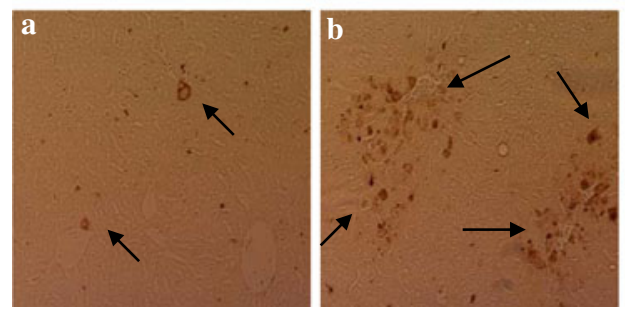

Fig. 3 LPS plus pyrazole toxicity is lowered in CYP2E1 knockout mice. a ALT/AST levels, b histopathology, a LPS plus pyrazole treated CYP2E1 knockout mice, $b$ LPS plus pyrazole treated wild type control. c TUNEL staining for DNA fragmentation; $a$ the

on the hepatotoxicity was determined. The TNF plus pyrazole elevation of transaminases was blunted by administration of SP600125 $(15 \mathrm{mg} / \mathrm{kg})$ or SB203580 $(15 \mathrm{mg} / \mathrm{kg})$. The MAPK inhibitors also lowered the necrosis (Fig. 6) and partially blocked the increased oxidative stress produced by the pyrazole plus $\mathrm{TNF} \alpha$ treatment, but had no effect on CYP2E1 activity or protein levels. These results suggest the CYP2E1 elevation of TNF $\alpha$ liver injury and oxidative stress is MAPK dependent. The activation of $\mathrm{JNK}$ in the pyrazole plus TNF $\alpha$ group was blocked by SP600125 but not SB203580 whereas the activation of p38 MAPK was blocked by SB203580 but not SP600125.

\section{Mitochondrial dysfunction}

Alcohol can cause mitochondrial dysfunction [8, 32]. We hypothesized that mitochondria are an eventual target for developing liver injury induced by TNF $\alpha$ when CYP2E1 is elevated by pyrazole. Initiation of a mitochondrial permeability transition was determined by assessing mitochondrial swelling in the absence and presence of $100 \mu \mathrm{M}$ calcium. Succinate $(10 \mathrm{mM})$ was the respiratory substrate. As shown in Fig. 7, in the absence of calcium, swelling (decrease in absorbance at $540 \mathrm{~nm}$ ) was low with all mitochondrial preparations although there was some basal swelling with the mitochondria from the pyrazole plus TNF $\alpha$-treated mice. The addition of $100 \mu \mathrm{M}$ calcium b

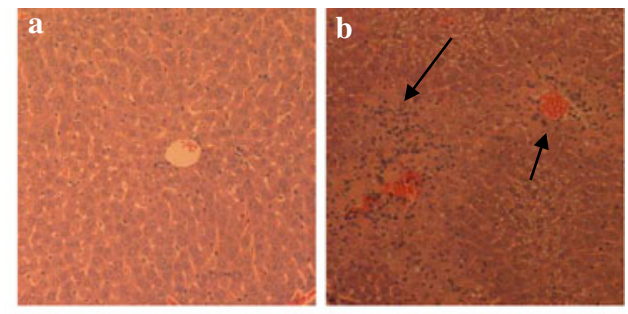

d

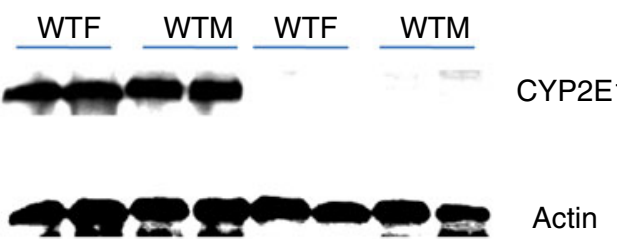

CYP2E1 null mice and $b$ wild type mice. d Immunoblot for CYP2E1 levels in wild type female or male mice $(W T F, W T M)$ or male and female CYP2E1 knockout mice ( $K O M, K O F)$

caused a low rate of swelling in the saline or TNF $\alpha$ alone mitochondria; swelling was somewhat elevated in the pyrazole alone mitochondria. Swelling was very rapid without any lag phase with the mitochondria from the pyrazole plus TNF $\alpha$-treated mice (Fig. 7). Importantly, this rapid swelling was blocked by cyclosporine A $(2 \mu \mathrm{M})$, a classic inhibitor of the mitochondrial permeability transition. Calcium elevates mitochondrial swelling in the saline-, $\mathrm{TNF} \alpha$ alone- and pyrazole alone groups, which was most pronounced in the TNF $\alpha$ plus pyrazole group. The calciuminduced swelling was sensitive to cyclosporine $\mathrm{A}$ in all groups. The basal swelling, in the absence of added calcium, was also higher in the TNF $\alpha$ plus pyrazole group, further suggestive of mitochondrial dysfunction.

The electrochemical potential of the proton gradient generated across the mitochondrial membrane $(\Delta \Psi)$ was assessed by monitoring fluorescence quenching of rhodamine 123. Addition of $10 \mathrm{mM}$ succinate at $1 \mathrm{~min}$ caused a decrease in fluorescence reflective of a high $\Delta \Psi$ corresponding to state 4 of respiration (Fig. 7). The decline in fluorescence averaged about 40 arbitrary units per minute with mitochondria from the saline or $\mathrm{TNF} \alpha$ alone treated mice and 30 arbitrary units per minute with mitochondria from the pyrazole-treated mice. However, the decline in fluorescence was only about 14 arbitrary units with mitochondria from the $\mathrm{TNF} \alpha$ plus pyrazole-treated mice. Addition of ADP at 3 min caused an enhancement of 

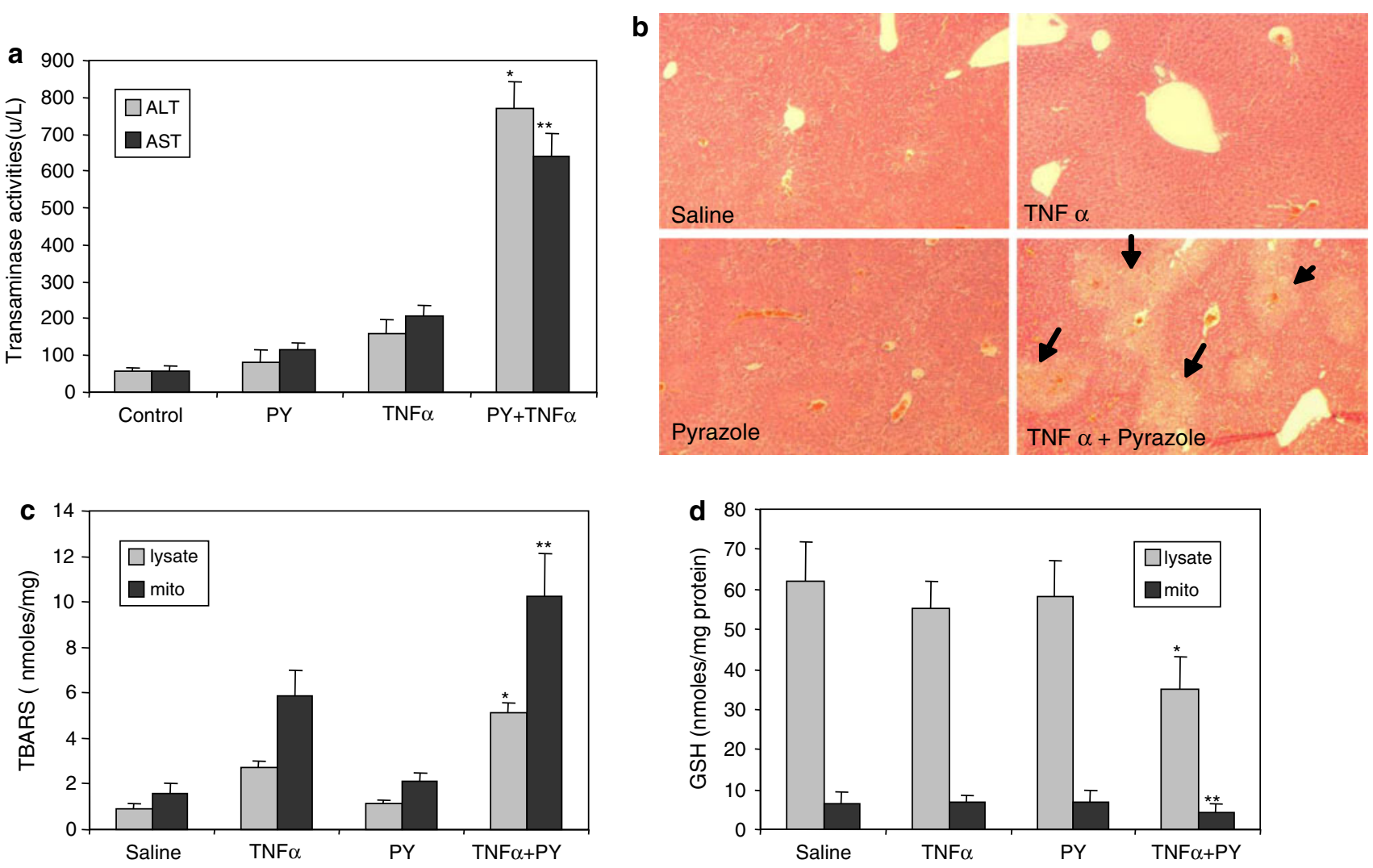

Fig. 4 Pyrazole potentiates TNF $\alpha$ hepatotoxicity and oxidative stress in mice. Mice were treated with either saline or pyrazole alone or $\mathrm{TNF} \alpha$ alone or pyrazole plus $\mathrm{TNF} \alpha$ followed by assays for a serum ALT/AST, b histopathology (arrows show necrotic zones), c lipid

peroxidation as reflected by levels of TBARs, and $\mathbf{d}$ GSH levels. TBARs and GSH were determined in liver cell lysates and in isolated mitochondrial fractions

fluorescence which corresponds to state 3 respiration as part of the proton motive force is utilized to synthesize ATP. This enhancement of fluorescence averaged 15, 14, 12 , and 4 arbitrary units per minute for mitochondria from the saline, TNF $\alpha$ alone, pyrazole alone and TNF $\alpha$ plus pyrazole treated mice, respectively. Taken as a whole, these initial data suggest a small decline in $\Delta \Psi$ in mitochondria from the pyrazole-treated mice and a more pronounced decline in mitochondria from the pyrazole plus $\mathrm{TNF} \alpha$-treated mice.

\section{TNF-RI and c-FLIP protein levels}

TNF-R1 is a cell surface molecule which initiates the majority of TNF $\alpha$ 's activities. c-FLIP acts as a caspase- 8 dominant negative regulator, blocking apoptosis. The levels of TNF-R1 and c-FLIP were determined in mice treated with saline, TNF $\alpha$ alone, pyrazole alone or $\mathrm{TNF} \alpha$ plus pyrazole. There were no differences in the levels of TNF-R1 among these four groups; thus, induction of CYP2E1 does not potentiate TNF $\alpha$ hepatotoxicity by changing TNF-R 1 levels. However, we did not observe significant liver injury when pyrazole plus LPS was given to TNF R1 knockout

mice, indicating that $\mathrm{TNF} \alpha$ binding to TNF-R1 is required to initiate the signaling leading ultimately to the liver injury. Levels of both c-FLIP ${ }_{\mathrm{L}}$ and c-FLIPs were lower in pyrazole alone- and pyrazole plus TNF $\alpha$-treated mice compared to saline- and TNF $\alpha$ alone-treated mice. Decreasing c-FLIP by pyrazole induction of CYP2E1 may be one of the possible mechanisms by which CYP2E1 potentiates TNF $\alpha$ induced liver injury. We suggest that although pyrazole alone lowers c-FLIP, little toxicity is found with pyrazole alone in the absence of TNF $\alpha$ i.e. 2 hits are necessary for liver injury. This decline in c-FLIP could be suggestive of a decline in NF- $\kappa \mathrm{B}$ signaling and activation since c-FLIP is a NF- $\kappa \mathrm{B}$ regulated gene.

\section{NF- $\kappa B$ activation pathway [97]}

NF-kB activation in Kupffer cells generally promotes liver injury because such activation results in the production of $\mathrm{TNF} \alpha$. However, NF-kB activation in hepatocytes generally protects against liver injury because NF-kB upregulates the synthesis of several hepatocyte protective factors. We evaluated whether the pyrazole induction of CYP2E1 could blunt TNF $\alpha$ activation of NF-kB in the hepatocyte 
Fig. 5 Pyrazole potentiation of $\mathrm{TNF} \alpha$ hepatotoxicity is blunted in CYP2E1 knockout mice as compared to SV129 wild type mice. $\mathrm{TNF} \alpha$ alone toxicity is low and similar in the wild type and CYP2E1 null mice, whereas $\mathrm{TNF} \alpha$ plus pyrazole toxicity is elevated in wild type but not in CYP2E1 knockout mice (note log scale for ALT/AST levels)

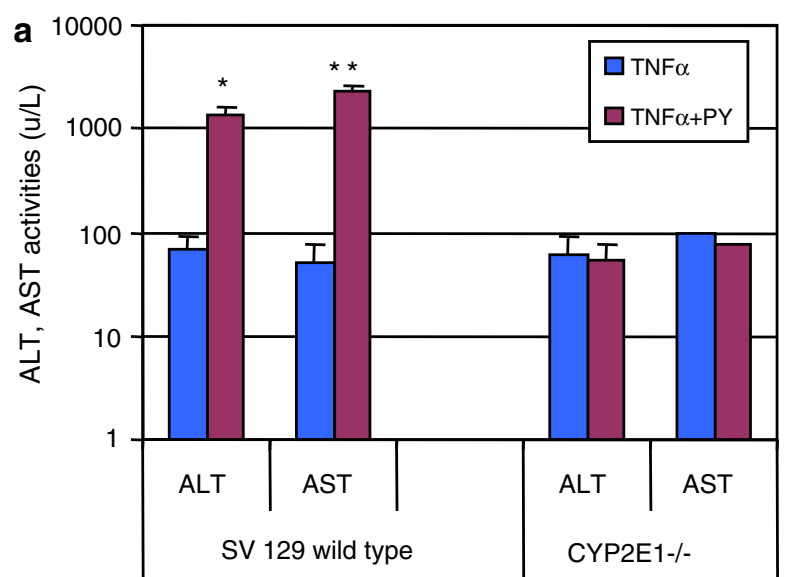

b
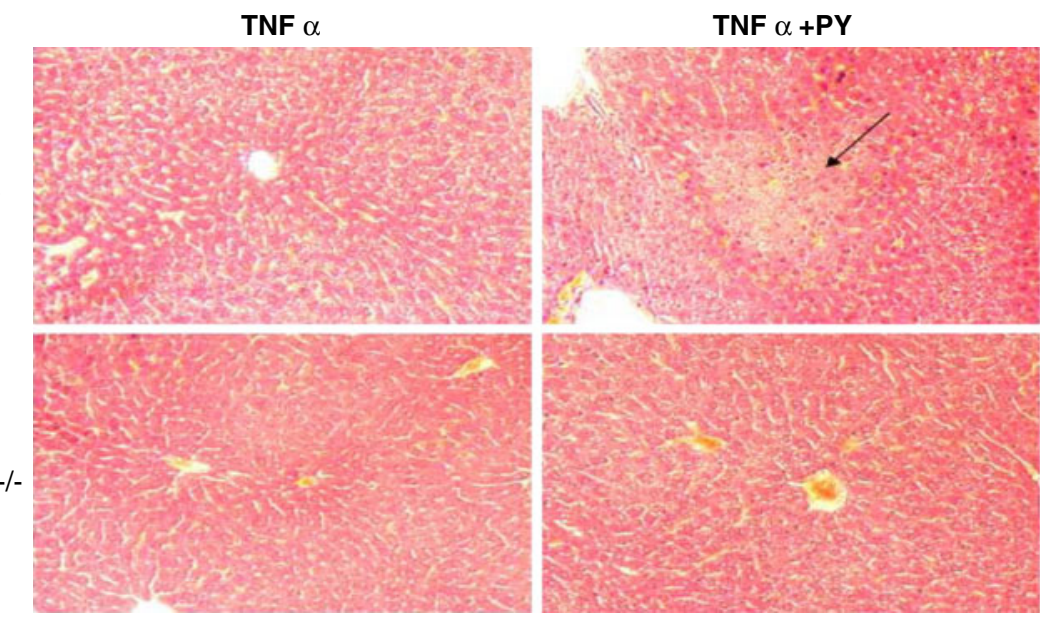

and thus block synthesis of hepatocyte protective factors. Levels of $\mathrm{I} \kappa \mathrm{B} \alpha$ were determined by Western blot. As expected, TNF $\alpha$ alone lowered the level of $\mathrm{I} \kappa \mathrm{B} \alpha$ compared to the saline control (Fig. 8) as TNF $\alpha$ activates the NF- $\kappa \mathrm{B}$ signaling pathway. In the presence of pyrazole plus $\mathrm{TNF} \alpha$, $\mathrm{I} \kappa \mathrm{B} \alpha$ levels were elevated compared to $\mathrm{TNF} \alpha$ alone. Pyrazole alone also raised $\mathrm{I} \kappa \mathrm{B} \alpha$ levels. This suggests that induction of CYP2E1 (ROS?) lowers, or prevents either phosphorylation (e.g. IKK activity is inhibited) or decay of $\mathrm{I} \kappa \mathrm{B} \alpha$; this would prevent activation of NF- $\kappa \mathrm{B}$ and therefore synthesis of NF- $\kappa \mathrm{B}-\mathrm{dependent}$ protective factors. Interestingly, levels of $\mathrm{I} \kappa \mathrm{B} \alpha$ are maintained, whereas levels of c-FLIP are lowered by pyrazole or pyrazole plus TNF $\alpha$; these two factors can contribute to the enhanced liver injury produced by pyrazole plus $\mathrm{TNF} \alpha$. NF- $\kappa \mathrm{B}$ binding activity was determined by ELISA (Active Motif). TNF $\alpha$ increased NF- $\kappa \mathrm{B}$ binding activity to $165 \%$ of the saline control. Pyrazole plus $\mathrm{TNF} \alpha$ reduced NF- $\kappa \mathrm{B}$ binding to $60 \%$ of the saline control (Fig. 8). Mn-SOD is an important antioxidant, which is increased by NF- $\kappa \mathrm{B}$ activation and serves to remove superoxide from the mitochondria. While $\mathrm{TNF} \alpha$ alone elevated Mn-SOD levels compared to saline or pyrazole alone, this increase was prevented in the presence of pyrazole, with Mn-SOD levels lower than the saline controls (Fig. 8). Thus, the treatment with pyrazole blocks activation of NF-kB by TNF.

\section{Effect of $N$-acetylcysteine (NAC)}

We evaluated the ability of NAC, a general antioxidant and a precursor of GSH, on the potentiation of TNF $\alpha$ toxicity by pyrazole as a proof of principle that oxidative stress plays an important role in the overall liver injury. C57BL/6 mice were treated with pyrazole for 2 days and then challenged with either saline or TNF $\alpha$. Some mice in each group were also treated with $150 \mathrm{mg} / \mathrm{kg}$ NAC on the second day of treatment with pyrazole and on day 3 prior to the challenge with TNF $\alpha$. Figure 9 shows that the elevation in ALT and AST and the necrosis caused by the pyrazole plus TNF $\alpha$ treatment were lowered by NAC. The increase in TBARs produced by pyrazole plus TNF $\alpha$ and the decline in liver GSH were both prevented by NAC (Fig. 9). Treatment with NAC had no effect on CYP2E1 protein levels or CYP2E1 catalytic activity. The activation of JNK 
a
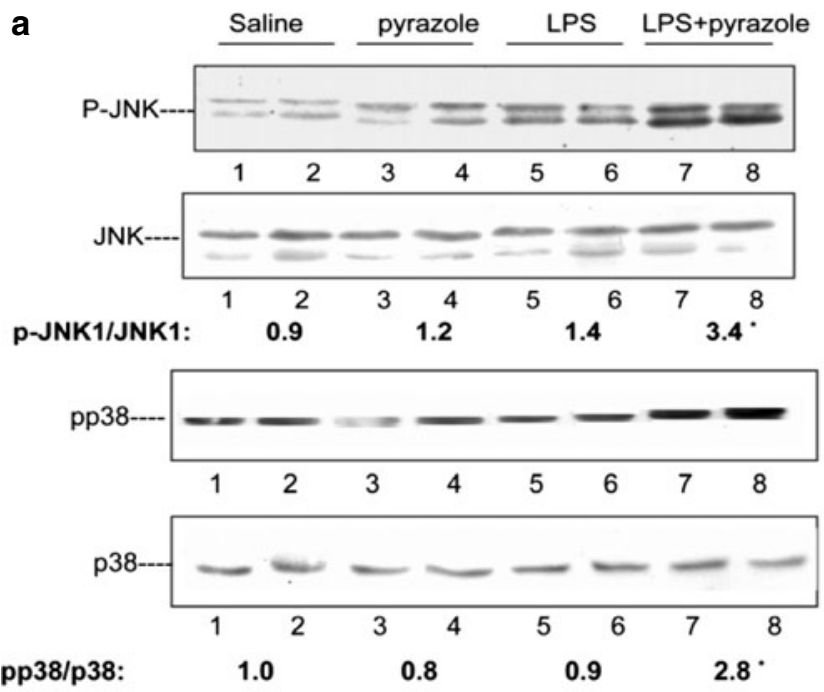

pp38/p38:

b
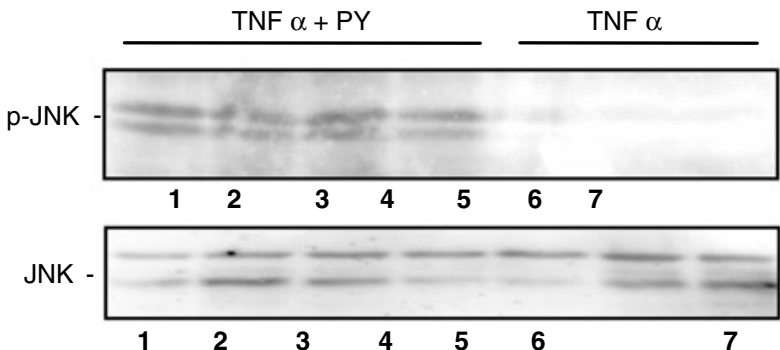

p-JNK/JNK: $0.78 \pm 0.15^{*}$

$0.10 \pm 0.00 \quad P<0.01$
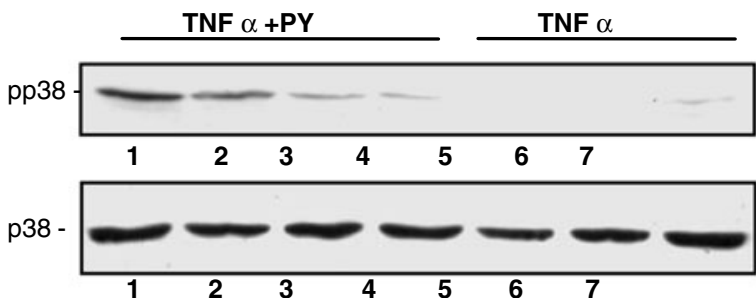

pp38/p38: $0.65 \pm 0.26$ *

$0.27 \pm 0.05 \quad P<0.01$

Fig. 6 a LPS plus pyrazole treatment activates JNK and p38 MAPK. b $\mathrm{TNF} \alpha$ plus pyrazole treatment activates JNK and p38 MAPK as compared to TNF $\alpha$ alone treatment. The pJNK/JNK and the pp38 MAPK/p38MAPK ratios are shown below the blots. $\mathbf{c}$ Either the JNK

or p38 MAPK by the pyrazole plus $\mathrm{TNF} \alpha$ treatment, compared to pyrazole alone, was blocked by NAC. The pyrazole plus TNF $\alpha$ treatment elevated levels of iNOS 2.6-fold, and this increase in iNOS was blunted by NAC to a 1.4-fold increase. Treating the TNF $\alpha$ plus pyrazole mice with NAC lowered the elevated $\mathrm{I} \kappa \mathrm{B} \alpha$ levels and restored $\mathrm{NF}-\kappa \mathrm{B}$ bindings to $145 \%$ of the saline control values (Fig. 8).These results with NAC suggest that elevated oxidative stress is central to the activation of JNK and p38 MAPK, to peroxynitrite formation, and to the liver injury produced by treatment with pyrazole plus TNF $\alpha$.
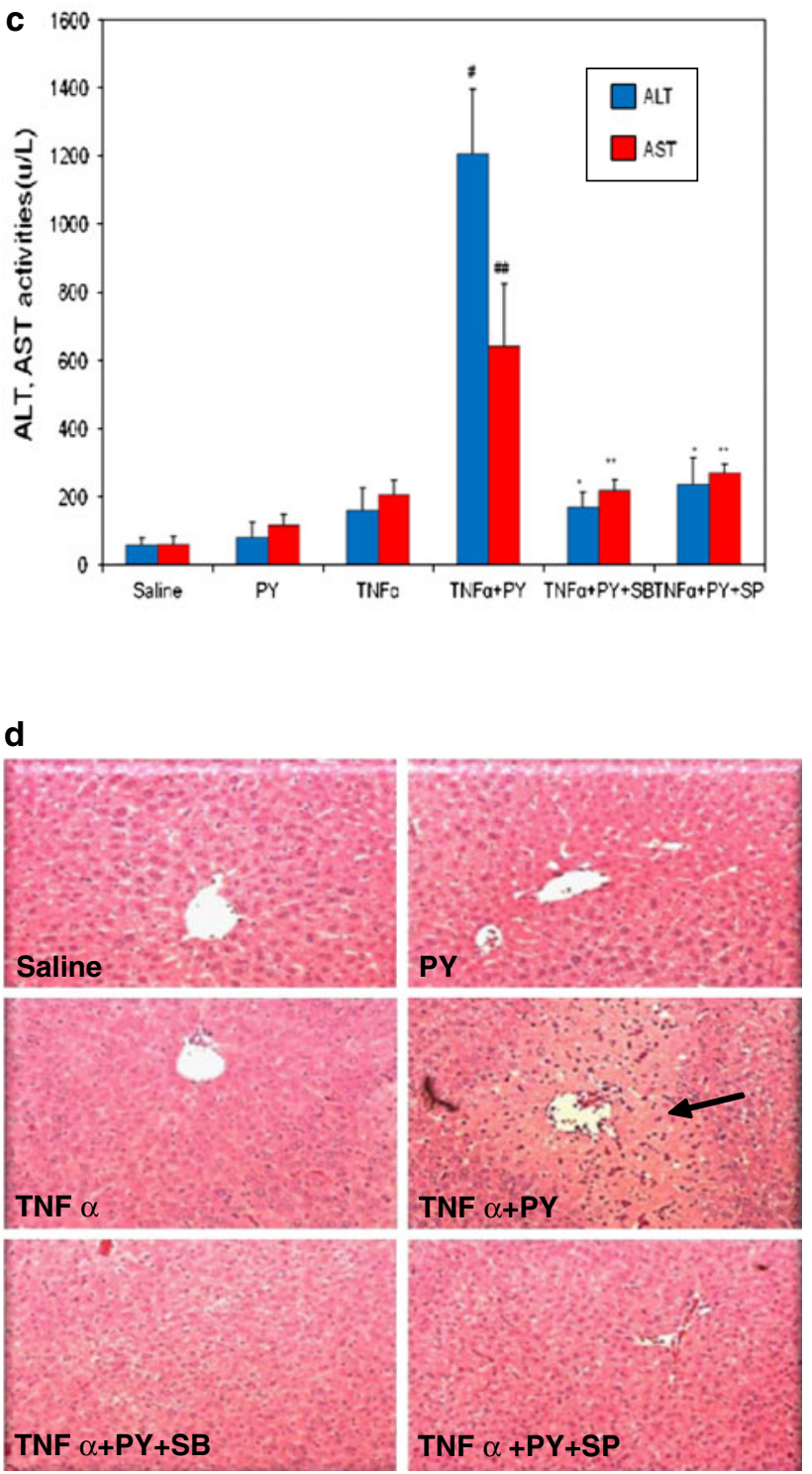

inhibitor SP600125 (SP) or the p38 MAPK inhibitor SB203508 (SB) prevent TNF $\alpha$ plus pyrazole-induced elevation of ALT and AST or d liver pathology

\section{Chronic ethanol treatment [58]}

Is there a role of CYP2E1 in the potentiation of chronic ethanol treatment on $\mathrm{TNF} \alpha$-induced liver injury? SV129 wild type and CYP2E1 knockout mice were fed the Lieber-DeCarli dextrose or ethanol liquid diet for 4 weeks and then challenged with saline or $4 \mathrm{mg} / \mathrm{kg}$ body weight LPS (055:B5, Sigma) IP and killed 8 h later. Ethanol alone caused a 3-fold and 2.2-fold increase in serum ALT levels in wild type mice and CYP2E1 knockout mice, respectively (Fig 10). LPS treatment caused a further increase in 


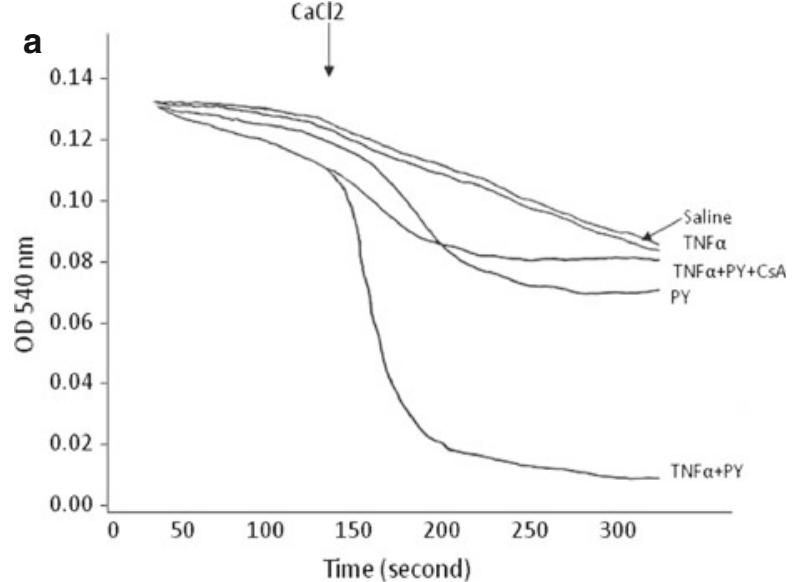

Fig. 7 Treatment with $\mathrm{TNF} \alpha$ plus pyrazole causes mitochondrial injury as reflected by a increased mitochondrial swelling (decreased absorbance at $540 \mathrm{~nm}$ ) or b decreased mitochondrial membrane potential as assayed by succinate-dependent decline in rhodamine 123

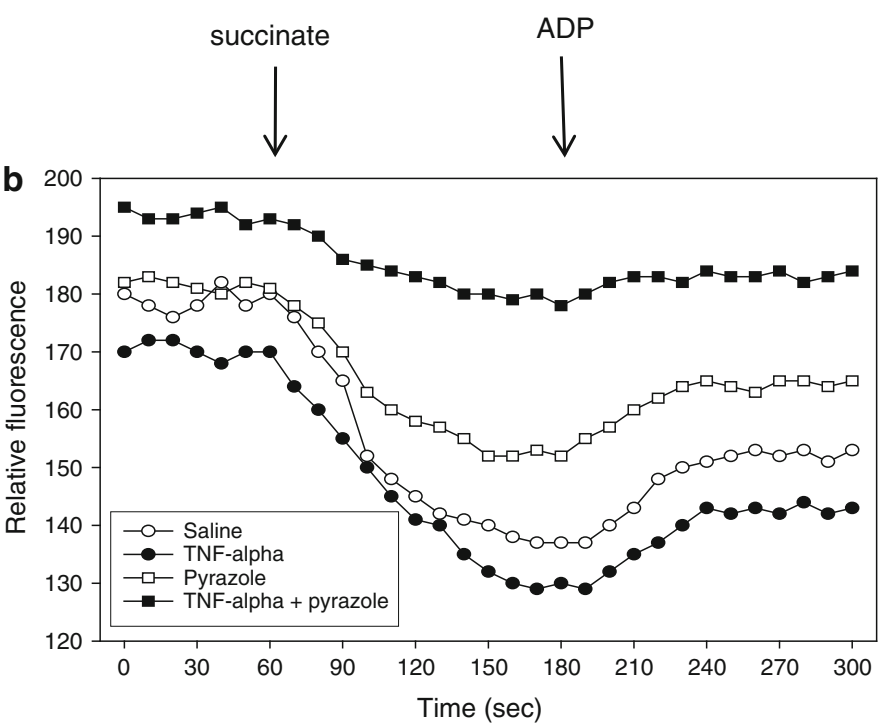

fluorescence. In a, the increased swelling produced by $\mathrm{TNF} \alpha$ plus pyrazole is prevented by cyclosporine A (CsA), an inhibitor of the mitochondrial permeability transition

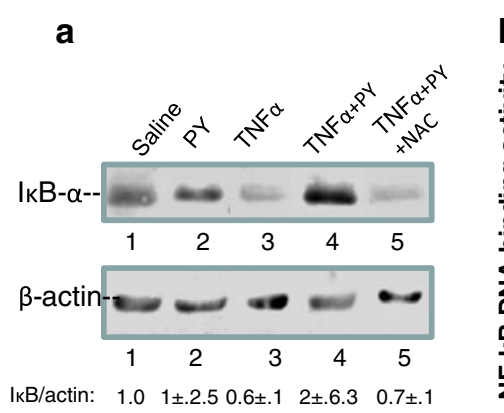

Fig. 8 Pyrazole prevents the activation of NF-kB by TNF $\alpha$. Levels of IkBalpha (a), NF-kB DNA binding (b) and content of SOD2 (manganese superoxide dismutase) after treatment with saline, pyrazole alone, $\mathrm{TNF} \alpha$ alone, or $\mathrm{TNF} \alpha$ plus pyrazole or $\mathrm{TNF} \alpha$ plus pyrazole plus the antioxidant $N$-acetylcysteine (NAC). Results show

serum ALT levels in the ethanol-fed wild type mice but not in the knockout mice (Fig. 10). LPS treatment had no effect in dextrose-fed mice. Pathological examination showed that more necroinflammatory foci were found in ethanol-fed wild type mice than in the ethanol-fed knockout mice $(3.2 \pm 1.7$ vs. $0.8 \pm 0.5, p<0.01)$ after being treated with LPS (Fig. 10, circles show inflammatory cell invasion and arrows show lipid droplets). CYP2E1 protein was absent in CYP2E1 knockout mice fed either dextrose or ethanol. CYP2E1 activity was increased about fourfold after ethanol feeding in wild type mice, but in CYP2E1 knockout mice fed dextrose or ethanol, rates of PNP oxidation were low. Induction of CYP2E1 can induce oxidative stress. After feeding with ethanol, the TBARs level the activation of NF-kB by $\mathrm{TNF} \alpha$ alone (decrease in IkBalpha, increased DNA binding, increased content of the antioxidant enzyme MnSOD) is prevented when TNF $\alpha$ plus pyrazole are administered. The TNF $\alpha$ activation of NF-kB is restored when NAC is administered to $\mathrm{TNF} \alpha$ plus pyrazole treated mice

increased about ninefold in wild type mice but only threefold in CYP2E1 knockout mice (Fig. 10). Thus, either pyrazole or ethanol induction of CYP2E1 potentiates LPS/ $\mathrm{TNF} \alpha$ hepatotoxicity.

\section{Pyrazole/TNF $\alpha$ hepatotoxicity in iNOS knockout mice}

The inducible nitric oxide synthase (iNOS) has been shown to play an important role in alcohol-induced liver injury [60]. We hypothesized that induction of CYP2E1 by pyrazole and induction of iNOS by LPS/TNF $\alpha$ results in the formation of the powerful oxidant peroxynitrite, ONOO, derived from the reaction between $\mathrm{O}_{2}^{-}$and NO. 3-Nitrotyrosine protein adducts (3-NT) were elevated in the 
b
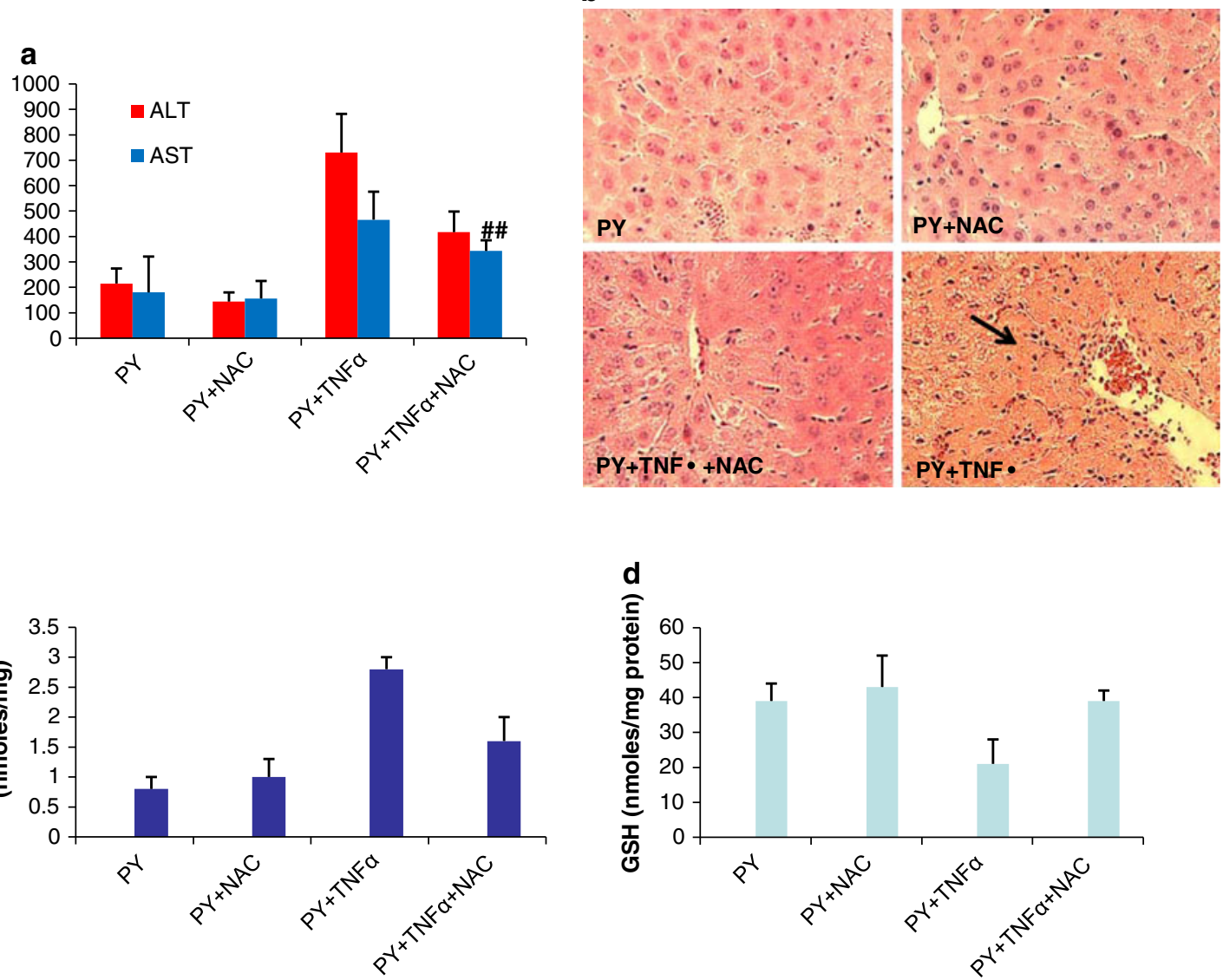

Fig. 9 The antioxidant N-acetylcysteine (NAC) decreases TNF $\alpha$ plus pyrazole-induced hepatotoxicity (a, b) and oxidative stress (c, d)

liver after pyrazole plus LPS treatment [55, 57]. We believe that ONOO plays a key role in the oxidative/ nitrosative stress and hepatotoxicity produced by the pyrazole plus LPS/TNF $\alpha$ treatment. If correct, oxidative/ nitrosative stress and hepatotoxicity produced by pyrazole plus LPS/TNF $\alpha$ treatment should be blunted in iNOS null mice. NOS2 (iNOS) knockout mice (B6-129P2) and genetic background control B6-129PF2/J mice were purchased from Jackson Laboratory and treated with saline or pyrazole alone or $\mathrm{TNF} \alpha$ alone or pyrazole plus TNF $\alpha$. The pyrazole plus TNF $\alpha$ treatment elevated ALT or AST levels about twofold $(P<0.05)$ in iNOS null mice as compared to treatment with saline or pyrazole alone or TNF $\alpha$ alone (Fig. 11). Pyrazole plus TNF $\alpha$ elevated ALT and AST about four to fivefold in the genetic background mice (Fig. 11) $(P<0.01$ compared to the increase in ALT and AST in iNOS null mice). In NOS2-/- mice, TNF $\alpha$ plus $\mathrm{PY}$ induced some hepatocyte degeneration change in the pericental area but no loci of necrosis were found. In the control wild type B6-129PF2/J mice, TNF $\alpha$ plus PY induced more severe liver injury and necrotic loci were found in several pericentral areas. TNF $\alpha$ plus PY slightly increased lipid peroxidation in NOS2- $/-$ mice compared with saline, PY or TNF $\alpha$ treated mice. Lipid peroxidation was more significantly elevated by TNF $\alpha$ plus PY treatment in B6-129PF2/J mice (4-fold increase) compared to the other groups and to the TNF $\alpha$ plus PY treated NOS2-/- mice (2-fold increase, Fig. 11). TNF $\alpha$ plus PY lowered GSH levels by $25 \%$ in NOS2-/- mice while a more pronounced decline in GSH occurred in the control mice (67\% decrease, Fig. 11). Levels of CYP2E1 were elevated to comparable extents by pyrazole in the wild type and the iNOS knockout mice (about 2.5 to 3 -fold), thus, the lower liver injury in the iNOS knockout mice is not due to lower levels of CYP2E1. These results suggest that while TNF $\alpha$ plus PY does induce some liver injury and oxidant stress in the NOS2-I- mice, a more severe liver injury and oxidant stress is induced by TNF $\alpha$ plus PY in the control mice. We hypothesize that NO derived from iNOS reacts with superoxide radical produced from CYP2E1 to generate the powerful oxidant peroxynitrite which plays a critical role in the liver injury produced by TNF plus pyrazole. The absence of iNOS in the knockout mice with the accompanying decline in NO would prevent formation of 

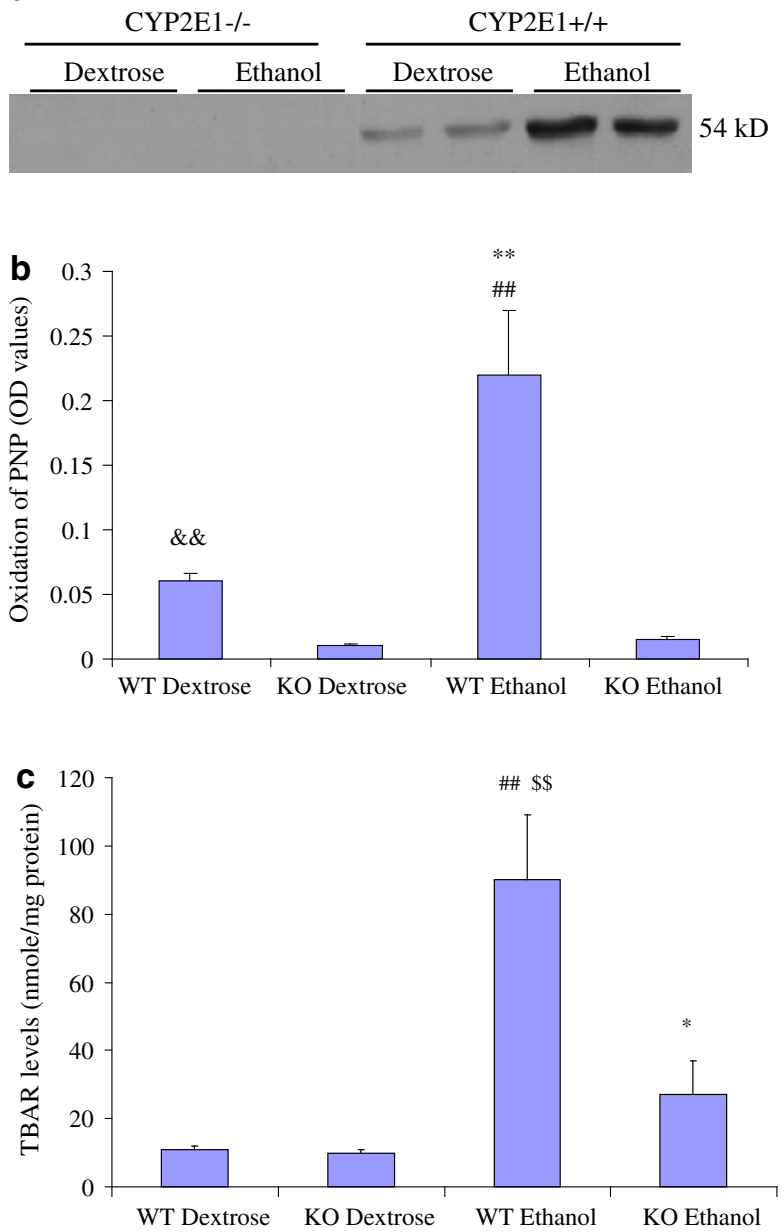

Fig. 10 LPS induces liver injury in chronic ethanol-fed wild type (WT) mice but not in CYP2E1 knockout mice (KO). a content of CYP2E1; b CYP2E1 catalytic activity (oxidation of p-nitrophenol); c levels of TBARs; $\mathbf{d}$ serum ALT and AST levels in saline-treated dextrose-fed and ethanol-fed WT and KO mice and in LPS-treated dextrose-fed and ethanol-fed WT and KO mice. Note that LPS increases transaminase levels in the ethanol-fed WT but not the

significant amounts of peroxynitrite even though superoxide continues to be produced from the elevated CYP2E1 and therefore liver injury is lowered.

\section{Cyclosporine A (CsA) prevents pyrazole plus LPS-induced liver injury [101]}

We evaluated whether cyclosporine A (CsA), an inhibitor of the mitochondrial permeability transition, could protect against the TNF $\alpha$ plus pyrazole-induced liver injury. Such an experiment could validate that mitochondrial dysfunction is a key downstream target in this injury. Male C57BL/6 mice were treated with saline, pyrazole, LPS, or pyrazole
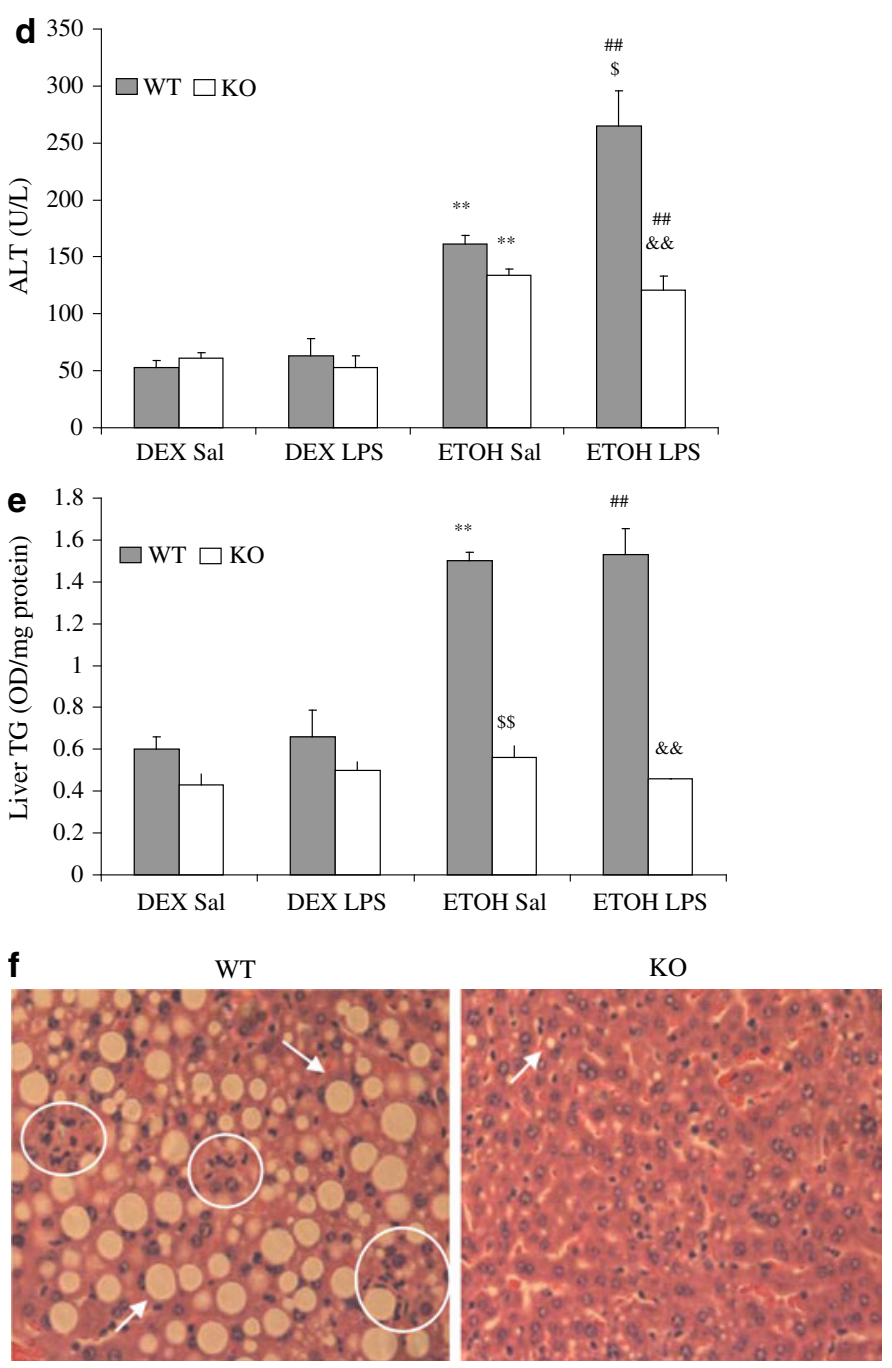

ethanol-fed CYP2E1 KO mice; e triglyceride levels. Note that ethanol increases the content of triglycerides in livers from WT mice but not CYP2E1 KO mice and that LPS has no effect on the ethanol-induced steatosis; f Liver pathology of ethanol plus LPS treated WT mice and CYP2E1 KO mice. Note that liver injury is produced by LPS in the ethanol-fed WT mice but not in the ethanol-fed CYP2E1 KO mice

plus LPS plus corn oil or pyrazole plus LPS plus 1 dose of CsA (100 mg/kg body wt, dissolved in corn oil). Serum ALT and AST levels were elevated in the PY + LPS + corn oil group compared to the other three groups. CsA treatment attenuated this increase in transaminases (Fig. 12). H\&E staining of liver tissue showed that the PY + LPS + corn oil treatment induced extensive liver zonal necrosis (circled in Fig. 12b) and that the CsA treatment prevented this. Mitochondrial swelling was increased in mitochondria isolated from the PY + LPS + corn oil treated mice compared to mitochondria from the saline + corn oil mice. The in vivo treatment with CsA prevented this increase in mitochondrial swelling, which likely 
Fig. $11 \mathrm{TNF} \alpha$ plus pyrazoleinduced hepatotoxicity (a) and oxidative stress $(\mathbf{b}, \mathbf{c})$ is decreased in iNOS knockout mice
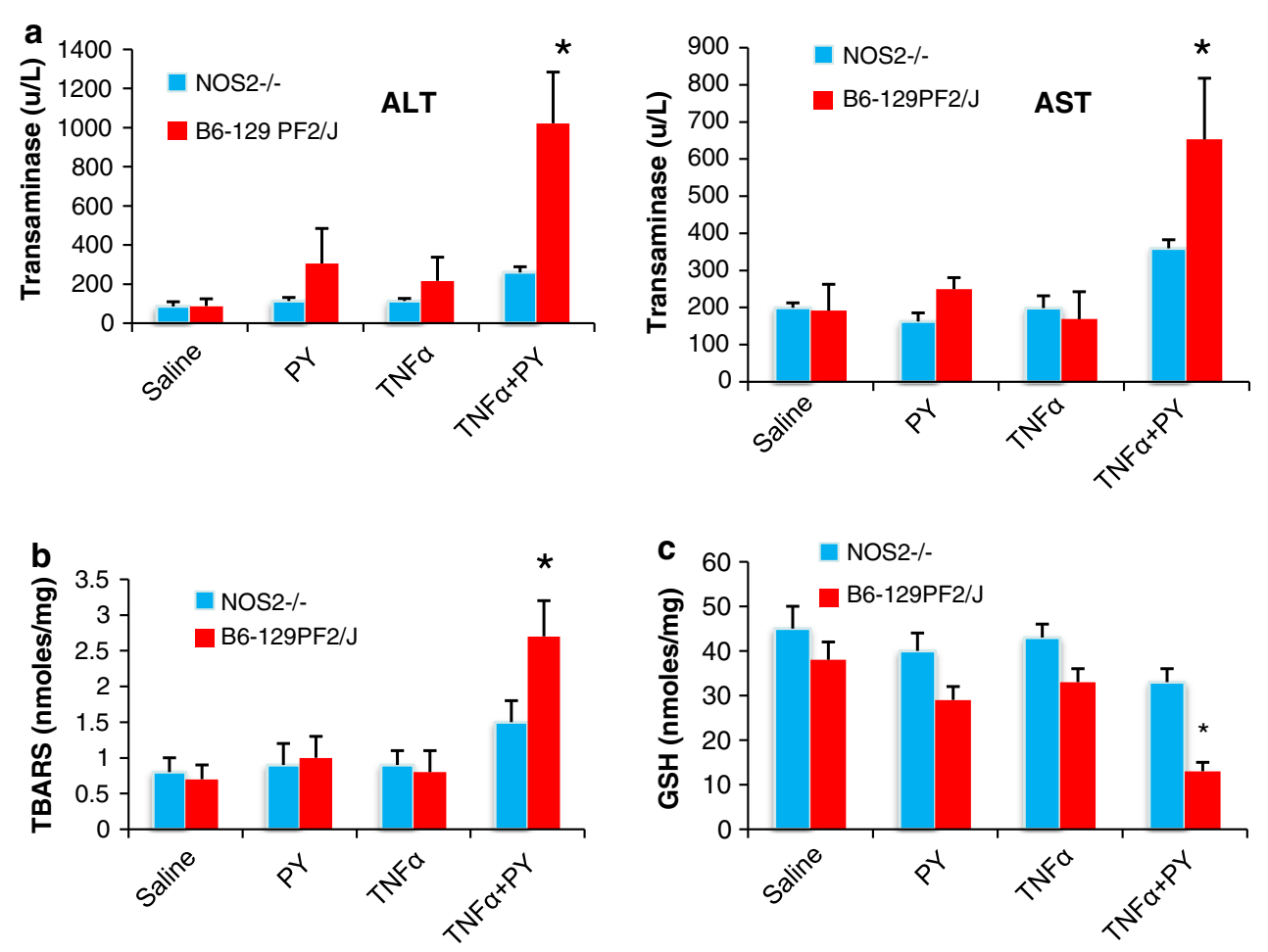
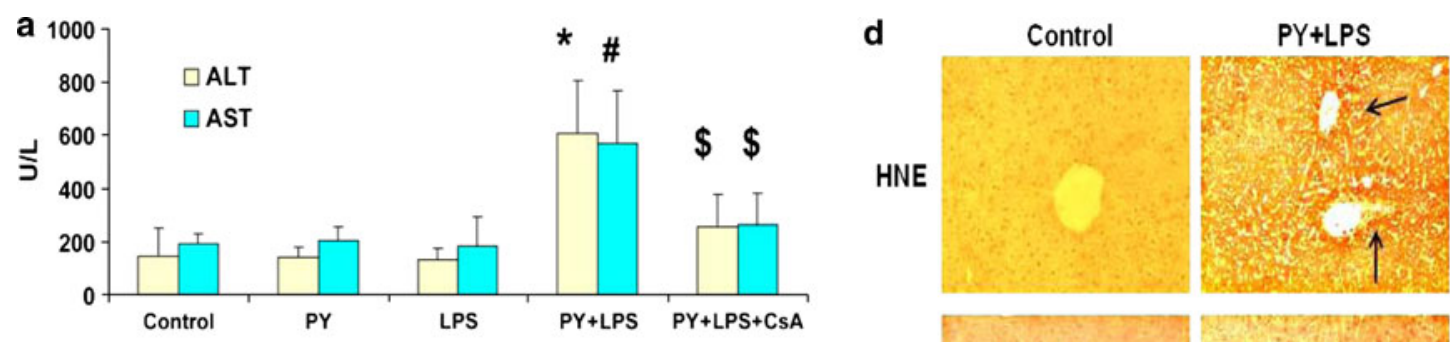

PY+LPS+CSA
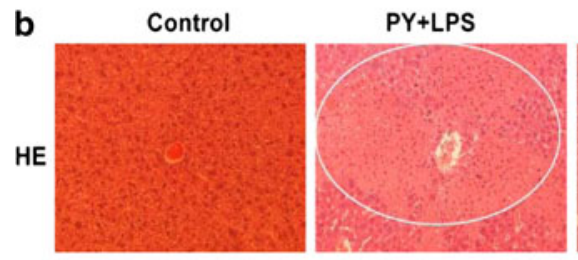

PY+LPS+CsA

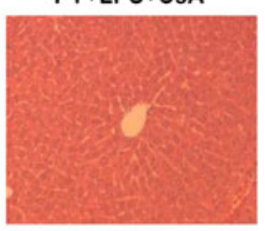

3-NT
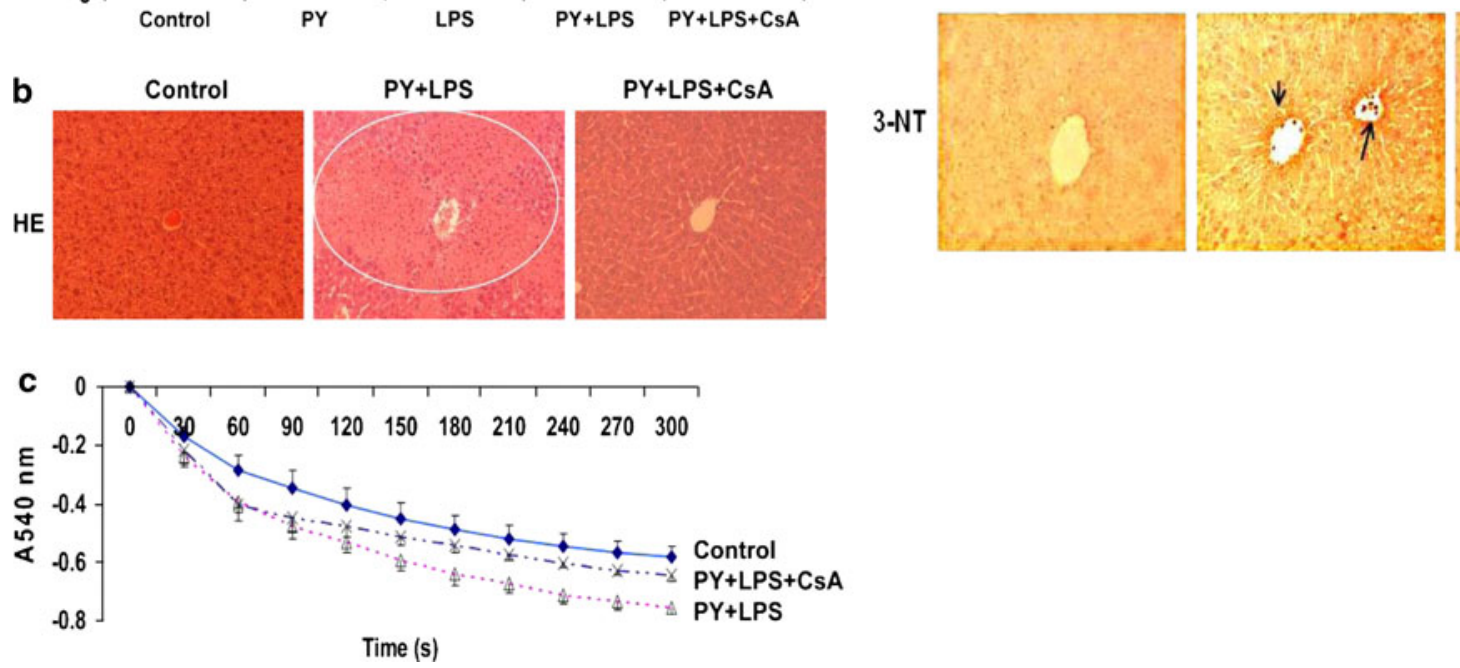

Fig. 12 The mitochondrial permeability transition inhibitor, cyclosporine A (CsA) lowers LPS plus pyrazole-induced liver injury (a, b), the increase in mitochondrial swelling (decrease in absorbance at $540 \mathrm{~nm}$ ) (c), and the elevated formation of 4-HNE and 3-NT protein adducts (d)

explains the protection against LPS plus pyrazole-induced liver injury. The LPS plus pyrazole elevation of 4-HNE and 3-NT protein adducts were also decreased by
CsA, suggesting that mitochondrial dysfunction plays an important role in the increase in oxidative/nitrosative stress. 


\section{Conclusions}

This review has focused on two major contributors to mechanisms by which ethanol causes liver injury, induction of CYP2E1 and elevated endotoxin (LPS) levels followed by increased production of TNF $\alpha$. Each of these has been extensively studied but there are few studies in which both factors have been evaluated simultaneously. We have shown that induction of CYP2E1 by pyrazole potentiates LPS- or TNF-induced hepatotoxicity. Evidence for a role for CYP2E1 comes from studies in which the CYP2E1 inhibitor CMZ blocks the liver injury, and from studies with CYP2E1 knockout mice where pyrazole plus LPS toxicity is blunted. The potentiated toxicity is associated with an increase in oxidative and nitrosative stress. Prevention of such increases, e.g. treatment with the antioxidant NAC or administration of TNF $\alpha$ plus pyrazole to iNOS knockout mice blunts the liver injury thus validating that the elevated oxidative/nitrosative stress plays a key role in producing the liver injury rather than occurs because of liver injury. JNK and P38 MAP kinases are activated by the combined pyrazole plus LPS/TNF $\alpha$ treatment. Preventing activation of JNK with SP600125 or activation of P38 MAPK with SB203580 decreases the liver injury. Inhibition of CYP2E1 or use of CYP2E1 knockout or iNOS knockout mice or preventing the oxidative/nitrosative stress decreases the activation of JNK and P38 MAPK.

$\mathrm{TNF} \alpha$ toxicity in hepatocytes is usually mitigated by activation of NF-kB protective factors. However, the TNF $\alpha$ activation of NF-kB is lost in the TNF $\alpha$ plus pyrazole treated mice with a subsequent decline in protective factors such as MnSOD. We hypothesize that the increase in oxidative/nitrosative stress, the decline in NF-kB protection, and the activation of MAPkinases ultimately affect mitochondrial integrity and function as shown by the increase in mitochondrial swelling and decline in mitochondrial membrane potential. Protection of mitochondrial integrity, e.g. with CsA, prevents the $\mathrm{TNF} \alpha$ plus pyrazole hepatotoxicity.

\section{Future studies}

Future studies are planned to evaluate molecular mechanisms for the activation of JNK and P38 MAPK, e.g. assaying MAPKK and MAPKKK, especially ASK-1 which is activated when ROS promote disassociation of the inhibitory thioredoxin; assaying MAPK phosphatases which are very sensitive to inhibition by ROS; evaluating whether there is a switch in toxicity from an initial apoptosis to necrosis as oxidative stress and impairment of mitochondrial function intensify. LPS toxicity was also increased by chronic ethanol consumption in wild type mice but not in CYP2E1 knockout mice. Future studies are planned to evaluate the role of CYP2E1 in ethanol potentiation of LPS/TNF $\alpha$ hepatotoxicity, following what has been learned in the pyrazole model with respect to roles of oxidative/nitrosative stress, iNOS, NF-kB, MAPK and mitochondrial dysfunction.

Acknowledgments Research conducted by the authors was supported by grants from The National Institute on Alcohol Abuse and Alcoholism/NIH.

Conflict of interest statement Nothing to declare.

\section{References}

1. Adachi M, Ishii H (2002) Role of mitochondria in alcoholic liver injury. Free Rad Biol Med 32:487-491

2. Adachi Y, Bradford BU, Gao W, Bojes HK, Thurman RG (1994) Inactivation of Kupffer cells prevents early alcoholinduced liver injury. Hepatology 20:453-460

3. Albano E (2006) Alcohol, oxidative stress and free radical damage. Proc Nutr Soc 65:278-290

4. Albano E, Clot P, Morimoto M, Tomasi A, Ingelman-Sundberg M, French S (1996) Role of Cytochrome P4502E1-dependent formation of hydroxyethyl free radicals in the development of liver damage in rats intragastrically fed with ethanol. Hepatology 23:155-163

5. Aleynik MK, Leo MA, Aleynik SI, Lieber CS (1999) Polyenylphosphatidyl-choline opposes the increase of Cytochrome P4502E1 by ethanol and corrects its iron-induced decrease. Alcohol Clin Exp Res 23:96-100

6. Bai JX, Cederbaum AI (2004) Adenovirus-mediated overexpression of CYP2E1 increases sensitivity of HepG2 cells to acetaminophen induced cytotoxicity. Mol Cell Biochem 262:165-176

7. Bai JX, Cederbaum AI (2006) Adenovirus-mediated expression of CYP2E1 produces liver toxicity in mice. Toxicol Sci 91:365371

8. Bailey SM (2003) A review of the role of reactive oxygen and nitrogen species in alcohol-induced mitochondrial dysfunction. Free Radic Res 37:585-596

9. Bailey SM, Cunningham CC (2002) Contribution of mitochondria to oxidative stress associated with alcoholic liver disease. Free Rad Biol Med 32:11-16

10. Bhagwandeen BS, Apte M, Manwarring L, Dickeson J (1987) Endotoxin induced hepatic necrosis in rats on an alcohol diet. J Pathol 152:47-53

11. Blanck J, Ristau O, Zhukov AA, Archakov AL, Rein H, Ruckpaul K (1991) Cytochrome P450 spin state and leakiness of the monoxygenease pathway. Xenobiotica 21:121-135

12. Bolt M, Koos PH, Their R (2003) The cytochrome P450 isoenzyme CYP2E1 in the biological processing of industrial chemicals. Int Arch Occup Environ Health 76:174-185

13. Bondy SC (1992) Ethanol toxicity and oxidative stress. Toxicol Lett 63:231-242

14. Bradford BU, Kono H, Isayama F, Kosyk O, Wheeler MD, Akiyama TE, Bleye L, Krausz KW, Gonzalez FJ, Koop DR, Rusyn I (2005) Cytochrome P450 CYP2E1, but not nicotinamide adenine dinucleotide phosphate oxidase, is required for ethanol-induced oxidative DNA damage in rodent liver. Hepatology 41:336-344 
15. Caro AA, Cederbaum AI (2004) Oxidative stress, toxicology, and pharmacology of CYP2E1. Annu Rev Pharmacol Toxicol 44:27-42

16. Castillo T, Koop DR, Kamimura S, Triadafilopoulos G, Tsukamoto H (1992) Role of cytochrome P4502E1 in ethanol, carbon tetrachloride and iron-dependent microsomal lipid peroxidation. Hepatology 16:992-996

17. Cederbaum AI (2001) Introduction serial review: alcohol, oxidative stress and cell injury. Free Rad Biol Med 31:1524-1526

18. Czaja MJ (2003) The future of GI and liver research: editorial perspectives. III. JNK/AP-1 regulation of hepatocyte death. Am. J. Physiol. Gastrointest. Liver Physiol 284:G875-G879

19. Deaciuc IV, Nikolova-Karakashian M, Fortunato F, Lee EY, Hill DB, McClain CJ (2000) Apoptosis and dysregulated ceramide metabolism in a murine model of alcohol-enhanced lipopolysaccharide hepatotoxicity. Alcohol Clin Exp Res 24:1557-1565

20. Dicker E, Cederbaum AI (1987) Hydroxyl radical generation by microsomes after chronic ethanol consumption. Alcohol Clin Exp Res 11:309-314

21. Donohue TM, Osna NA, Clemens DL (2006) Recombinant Hep G2 cells that express alcohol dehydrogenase and cytochrome P450 2E1 as a model of ethanol-elicited cytotoxicity. Int J Biochem Cell Biol 38:92-101

22. Ekstrom G, Ingelman-Sundberg M (1989) Rat liver microsomal NADPH-supported oxidase activity and lipid peroxidation dependent on ethanol-inducible cytochrome P-450 (P-450IIE1). Biochem Pharmacol 38:1313-1319

23. Enomoto N, Ikejima K, Yamashina S, Hirose M, Shimizu H, Kitamura T, Takei Y, Sato And N, Thurman RG (2001) Kupffer cell sensitization by alcohol involves increased permeability to gut-derived endotoxin. Alcohol Clin Exp Res 25(6 Suppl):51S$54 \mathrm{~S}$

24. French SW, Wong K, Jui L, Albano E, Hagbjork AL, IngelmanSundberg M (1993) Effect of ethanol on cytochrome P450 2E1 (CYP2E1), lipid peroxidation, and serum protein adduct formation in relation to liver pathology pathogenesis. Exp Mol Pathol 58:61-75

25. French SW, Morimoto M, Reitz RC, Koop D, Klopfenstein B, Estes K, Clot P, Ingelman-Sundberg M, Albano E (1997) Lipid peroxidation, CYP2E1 and arachidonic acid metabolism in alcoholic liver disease in rats. J Nutr 127:907S-911S

26. Girre C, Lucas D, Hispard FR, Menez C, Dally S, Menez JP (1994) Assessment of cytochrome P4502E1 in induction in alcoholic patients by chlorzoxazone pharmacokinetics. Biochem Pharmacol 47:1503-1508

27. Gorsky LD, Koop DR, Coon MJ (1984) On the stoichiometry of the oxidase and monooxygenase reactions catalyzed by liver microsomal cytochrome P450. J Biol Chem 259:6812-6817

28. Gouillon Z, Lucas D, Li J, Hagbjork AL, French BA, Fu P, Fang C, Ingelman-Sundberg M, Donohue TM Jr, French SW (2000) Inhibition of ethanol-induced liver disease in the intragastric feeding rat model by chlormethiazole. Proc Soc Exp Biol Med 224:302-308

29. Gunawan BK, Liu ZX, Han D, Hanawa N, Gaarde WA, Kaplowitz N (2006) c-Jun N-terminal kinase plays a major role in murine acetaminophen hepatotoxicity. Gastroenterology 131:165-178

30. Hansen J, Cherwitz DL, Allen JI (1994) The role of tumor necrosis factor-alpha in acute endotoxin-induced hepatotoxicity in ethanol-fed rats. Hepatology 20:461-474

31. Hewett JA, Jean PA, Kunkel SL, Roth RA (1993) Relationship between tumor necrosis factor-alpha and neutrophils in endotoxin-induced liver injury. Am J Physiol 265:G1011-G1015

32. Hoek JB, Cahill A, Pastorino JG (2002) Alcohol and mitochondria: a dysfunctional relationship. Gastroenterology 122:2049-2063
33. Honchel R, Ray MB, Marsano L, Cohen D, Lee E, Shedlofsky S, McClain CJ (1992) Tumor necrosis factor in alcohol enhanced endotoxin liver injury. Alcohol Clin Exp Res 16:665-669

34. Iimuro Y, Gallucci RM, Luster MI, Kono H, Thurman RG (1997) Antibodies to tumor necrosis factor alpha attenuate hepatic necrosis and inflammation caused by chronic exposure to ethanol in the rat. Hepatology 26:1530-1537

35. Iimuro Y, Bradford BU, Yamashina S, Rusyn I, Nakagami M, Enomoto N, Kono H, Frey W, Forman D, Brenner D, Thurman RG (2000) The glutathione precursor L-2-oxothiazolidine4-carboxylic acid protects against liver injury due to chronic enteral ethanol exposure in the rat. Hepatology 31:391-398

36. Kamimura S, Tsukamoto H (1995) Cytokine gene expression by Kupffer cells in experimental alcoholic liver disease. Hepatology 22:1304-1309

37. Kim ND, Kwak MK, Kim SG (1997) Inhibition of cytochrome P4502E1 expression by 2-(allylthio) pyrazine a protential chemo-protective agent: hepatoprotective effects. Biochem Pharmacol 53:261-269

38. Klein SM, Cohen G, Lieber CS, Cederbaum AI (1983) Increased microsomal oxidation of hydroxyl radical scavenging agents and ethanol after chronic consumption of ethanol. Arch Biochem Biophys 223:425-433

39. Knecht KT, Adachi Y, Bradford B, Iimuro Y, Kadiiska M, Qun-Hue X, Thurman RG (1995) Free radical adducts in the bile of rats treated chronically with intragastric alcohol. Mol Pharmacol 47:1028-1034

40. Kono H, Bradford BU, Yin M, Sulik KK, Koop DR, Peters JM, Gonzalez FJ, McDonald T, Dikalova A, Kadiiska MB, Mason RP, Thurman RG (1999) CYP2E1 is not involved in early alcohol-induced liver injury. Am J Physiol 277:G1259-G1267

41. Kono H, Rusyn I, Yin M, Gäbele E, Yamashina S, Dikalova A, Kadiiska MB, Connor HD, Mason RP, Segal BH, Bradford BU, Holland SM, Thurman RG (2000) NADPH oxidase-derived free radicals are key oxidants in alcohol-induced liver disease. J Clin Invest 106:867-872

42. Kono H, Rusyn I, Uesugi T, Yamashina S, Connor HD, Dikalova A, Mason RP, Thurman RG (2001) Diphenyleneiodonium sulfate, an NADPH oxidase inhibitor, prevents early alcoholinduced liver injury in the rat. Am J Physiol Gastrointest Liver Physiol 280:G1005-G1012

43. Koop DR (1992) Oxidative and reductive metabolism by cytochrome P4502E1. FASEB J. 6:724-730

44. Koop DR, Klopfenstein B, Iimuro Y, Thurman RG (1997) Gadolinium chloride blocks alcohol-dependent liver tocicity in rats treated chronically with intragastric alcohol despite the induction of CYP2E1. Mol Pharmacol 51:944-950

45. Korourian S, Hakkak R, Ronis MJ, Shelnut SR, Waldron J, Ingelman-Sundberg M, Badger TM (1999) The effects of enteral nutrition and chronic alcohol on hepatic necrosis. Toxicol Sci 47:110-117

46. Koteish A, Yang S, Lin H, Huang X, Diehl AM (2002) Chronic ethanol exposure potentiates lipopolysaccharide liver injury despite inhibiting Jun N-terminal kinase and caspase 3 activation. J Biol Chem 277:13037-13044

47. Kurose I, Higuchi H, Kato S, Miura S, Watanabe N, Kamegaya Y, Tomita K, Takaishi M, Horie Y, Fukuda M, Mizukami K, Ishii H (1997) Oxidative stress on mitochondria and cell membrane of cultured rat hepatocytes and perfused liver exposed to ethanol. Gastroenterology 112:1331-1343

48. Lee SST, Buters JTM, Pineau T, Fernandez-Salguero P, Gonzalez FJ (1996) Role of CYP2E1 in the hepatotoxicity of acetaminophen. J. Biol. Chem. 271:12063-12067

49. Li J, French BA, Riley N, Bardag-Gorce F, Fu P, French SW (2001) Oral low carbohydrate liquid diet induces experimental steatohepatitis in the rat. Exp Mol Pathol 71:132-136 
50. Lieber CS (1997) Cytochrome P4502E1; its physiological and pathological role. Physiol Rev 77:517-544

51. Lieber CS, Leo MA, Aleynik SI, Aleynik MK, DeCarli LM (1997) Polyenylphosphatidylcholine decreases alcohol-induced oxidative stress in the baboon. Alcohol Clin Exp Res 21:375379

52. Lindros K, Jarvelainen H (1998) A new oral low-carbohydrate alcohol liquid diet producing liver lesions: A preliminary account. Alcohol 33:347-353

53. Liu H, Lo CR, Czaja MJ (2002) NF-kappaB inhibition sensitizes hepatocytes to TNF-induced apoptosis through a sustained activation of JNK and c-Jun. Hepatology 35:772-778

54. Liu H, Jones BE, Bradham C, Czaja MJ (2002) Increased cytochrome P-450 2E1 expression sensitizes hepatocytes to c-Jun-mediated cell death from TNF-alpha. Am J Physiol Gastrointest Liver Physiol 282:G257-G266

55. Lu Y, Cederbaum AI (2006) Enhancement by pyrazole of lipopolysaccharide-induced liver injury in mice: role of cytochrome P450 2E1 and 2A5. Hepatology 44:263-274

56. Lu Y, Cederbaum AI (2008) CYP2E1 and oxidative liver injury by alcohol. Free Radic Biol Med 44:723-738

57. Lu Y, Wang X, Cederbaum AI (2005) Lipopolysaccharideinduced liver injury in rats treated with the CYP2E1 inducer pyrazole. Am J Physiol Gastrointest Liver Physiol 289:G308G319

58. Lu Y, Zhuge J, Wang X, Bai J, Cederbaum AI (2008) Cytochrome P450 2E1 contributes to ethanol-induced fatty liver in mice. Hepatology 47:1483-1494

59. Mathurin P, Deng QG, Keshavarzian A, Choudhary S, Holmes EW, Tsukamoto H (2000) Exacerbation of alcoholic liver injury by enteral endotoxin in rats. Hepatology 32:1008-1017

60. McKim SE, Gabele E, Isayama F, Lambert JC, Tucker LM, Wheeler MD, Connor HD, Mason RP, Doll MA, Hein DW, Arteel GE (2003) Inducible nitric oxide synthase is required in alcohol-induced liver injury: studies with knockout mice. Gastroenterology 125:1834-1844

61. Morgan K, French SW, Morgan TR (2002) Production of a cytochrome P450 2E1 transgenic mouse and initial evaluation of alcoholic liver damage. Hepatology 36:122-134

62. Morimoto M, Hagbjork AL, Nanji AA, Ingelman-Sundberg M, Lindros KO, Fu PC, Albano E, French SW (1993) Role of cytochrome P450 2E1 in alcoholic liver disease pathogenesis. Alcohol 10:459-464

63. Morimoto M, Zern MA, Hagbjork AL, Ingelman-Sundberg M, French SW (1994) Fish oil, alcohol and liver pathology: role of cytochrome P450 2E1. Proceedings Society of Experimental Biology and Medicine. 207:197-205

64. Morimoto M, Hagbjork AL, Wan YJ, Fu PC, Clot P, Albano E, Ingelman-Sundberg M, French SW (1995) Modulation of experimental alcohol-induced liver disease by cytochrome P450 2E1 inhibitors. Hepatology 21:1610-1617

65. Nanji AA, Zhao S, Sadrzadeh SMH, Dannenberg AJ, Tahan SR, Waxman DJ (1994) Markedly enhanced cytochrome P4502E1 induction and lipid peroxidation is associated with severe liver injury in fish oil-ethanol-fed rats. Alcohol Clin Exp Res 18:1280-1285

66. Nanji AA, Khettry U, Sadrzadeh SM (1994) Lactobacillus feeding reduces endotoxemia and severity of experimental alcoholic liver disease. Proc Soc Exp Biol Med 205:243-247

67. Nordman R, Riviere C, Rouach H (1992) Implication of free radical mechanisms in ethanol-induced cellular injury. Free Rad Biol Med 12:219-240

68. Osna NA, Clemens DL, Donohue TM Jr (2003) Interferon gamma enhances proteasome activity in recombinant Hep G2 cells that express cytochrome P4502E1: modulation by ethanol. Biochem Pharmacol 66:697-710
69. Pastorino JG, Hoek JB (2000) Ethanol potentiates tumor necrosis factor-alpha cytotoxicity in hepatoma cells and primary rat hepatocytes by promoting induction of the mitochondrial permeability transition. Hepatology $31: 1141-1152$

70. Pastorino JG, Shulga N, Hoek JB (2003) TNF-alpha-induced cell death in ethanol-exposed cells depends on p38 MAPK signaling but is independent of Bid and caspase-8. Am J Physiol Gastrointest Liver Physiol. 285:G503-G516

71. Puntarulo S, Cederbaum AI (1988) Increased NADPH-dependent chemiluminescence by microsomes after chronic ethanol consumption. Arch Biochem Biophys 266:435-445

72. Purohit V, Brenner DA (2006) Mechanisms of alcohol-induced hepatic fibrosis: a summary of the Ron Thurman Symposium. Hepatology 43:872-878

73. Rao RK, Seth A, Sheth P (2004) Recent Advances in Alcoholic Liver Disease I Role of intestinal permeability and endotoxemia in alcoholic liver disease. Am J Physiol Gastrointest Liver Physiol. 286:G881-G884

74. Rashba-Step J, Turro NJ, Cederbaum AI (1993) Increased $\mathrm{NADPH}-$ and NADH-dependent production of superoxide and hydroxyl radical by microsomes after chronic ethanol treatment. Arch Biochem Biophys 300:401-408

75. Raucy JL, Kraner JC, Lasker JM (1993) Bioactivation of halogenated hydrocarbons by cytochrome P4502E1. Crit Rev Toxicol 23:1-20

76. Ronis MJJ, Huange J, Crouch J, Mercadao C, Irby D, Valentine CR, Lumpkin CK, Ingelman-Sundberg M, Badger TM (1993) Cytochrome P450 CYP2E1 induction during chronic alcohol exposure occurs by a two-step mechanism associated with blood alcohol concentrations in rats. J Pharmacol Exp Ther 264:944950

77. Ronis MJJ, Lindros KO, Ingelman-Sundberg M (1996) The CYP2E subfamily. In: Ioannides C (ed) Cytochromes P450. Metabolic and toxicological aspects. CRC Press, New York, pp 211-239

78. Schattenberg JM, Singh R, Wang Y, Lefkowitch JH, Rigoli RM, Scherer PE, Czaja MJ (2006) JNK1 but not JNK2 promotes the development of steatohepatitis in mice. Hepatology 43:163-172

79. Song BJ, Cederbaum AI, Koop DR, Ingelman-Sundberg M, Nanji A (1996) Ethanol-inducible cytochrome P450 (CYP2E1): biochemistry, molecular biology and clinical relevance. Alcohol Clin Exp Res 20(Suppl):138A-146A

80. Su GL (2002) Lipopolysaccharides in liver injury: molecular mechanisms of Kupffer cell activation. Am J Physiol Gastrointest Liver Physiol 283:G256-G265

81. Suzuki S, Nakamura S, Serizawa A, Sakaguchi T, Konno H, Muro H, Kosugi I, Baba S (1996) Role of Kupffer cells and the spleen in modulation of endotoxin-induced liver injury after partial hepatectomy. Hepatology 24:219-225

82. Takei Y, Arteel GE, Bergheim I, Lambert JC, McMullen MR, Nagy LE, Enomoto N, Sato N (2005) Roles of Kupffer cells in alcoholic liver disease. Alcohol Clin Exp Res 29:1116-1120

83. Tanaka E, Terada M, Misawa S (2000) Cytochrome P450 2E1: its clinical and toxicological role. J Clin Pharm Ther 25:165-175

84. Thurman RG (1998) Mechanisms of hepatic toxicity II. Alcoholic liver injury involves activation of Kupffer cells by endotoxin. Am J Physiol 275:G605-G611

85. Tsukamoto H (2000) CYP2E1 and ALD. Hepatology 32:154155

86. Tsukamoto H (2001) How is the liver primed or sensitized for alcoholic liver disease? Alcohol Clin. Exp. Res. 25:171S-181S

87. Tsukamoto H, Lu SC (2001) Current concepts in the pathogenesis of alcoholic liver injury. FASEB Journal. 15:1335-1349

88. Tsukamoto H, Horne W, Kamimura S, Niemela O, Parkkila S, Yla-Herttuala S, Brittenham GM (1995) Experimental liver cirrhosis induced by alcohol and iron. J Clin Invest 96:620-630 
89. Uehara T, Bennett B, Sakata ST, Satoh Y, Bilter GK, Westwick JK, Brenner DA (2005) JNK mediates hepatic ischemia reperfusion injury. J Hepatol 42:850-859

90. Uesugi T, Froh M, Arteel GE, Bradford BU, Gäbele E, Wheeler MD, Thurman RG (2001) Delivery of IkappaB superrepressor gene with adenovirus reduces early alcohol-induced liver injury in rats. Hepatology 34:1149-1157

91. Wang JH, Redmond HP, Watson RW, Bouchier-Hayes D (1995) Role of lipopolysaccharide and tumor necrosis factor-alpha in induction of hepatocyte necrosis. Am J Physiol 269:G297-G304

92. Wheeler MD, Thurman RG (2001) The role of Kupffer cell oxidant production in early ethanol-induced liver disease. Free Rad Biol Med 31:1544-1549

93. White RE (1991) The involvement of free radicals in the mechanisms of monooxygenases. Pharmacol Ther 49:21-42

94. Wu D, Cederbaum AI (1996) Ethanol toxicity to a transfected HepG2 cell line expressing human cytochrome P450 2E1. J Biol Chem 271:23914-23919

95. Wu D, Cederbaum AI (1999) Ethanol-induced apoptosis to stable HepG2 cell lines expressing human cytochrome P450 2E1. Alcohol Clin Exp Res 23:67-76
96. Wu D, Cederbaum AI (2008) Cytochrome P4502E1 sensitizes to tumor necrosis factor alpha-induced liver injury through activation of mitogen-activeted protein kineses in mice. Hepatology 47:1005-1017

97. Wu D, Xu C, Cederbaum A (2009) Role of nitric oxide and nuclear factor-kappaB in the CYP2E1 potentiation of tumor necrosis factor alpha hepatotoxicity in mice. Free Radic Biol Med 46:480-491

98. Yang CS, Yoo JSH, Ishizaki H, Hong J (1990) Cytochrome P450IIE1 Roles in nitrosamine metabolism and mechanisms of regulation. Drug Metab Rev 22:147-159

99. Yin XM, Ding WX (2003) Death receptor activation-induced hepatocyte apoptosis and liver injury. Curr Mol Med 3:491-508

100. Yin M, Wheeler MD, Kono H, Bradford BU, Galluci RM, Luster MI, Thurman RG (1999) Essential role of TNF $\alpha$ in alcohol-induced liver injury in mice. Gastroenterology 117:942952

101. Zhuge J, Cederbaum AI (2009) Inhibition of the mitochondrial permeability transition by cyclosporin A prevents pyrazole plus lipopolysaccharide-induced liver injury in mice. Free Radic Biol Med 46:406-413 